\title{
Hacia la utopía concreta: crítica y prospección para la Ciudad Puerto de Antofagasta, Chile
}

Towards the concrete utopia: a critique and prospections for Antofagasta's City-Port, Chile

\section{José Francisco Vergara-Perucich* y Alberto Texido Zlatar**}

Recibido: 01 de agosto de 2018

Aceptado: 04 de diciembre de 2018

\section{Resumen}

El Puerto de Antofagasta es una infraestructura urbana ha sido foco de diversos problemas socio-espaciales históricos en la ciudad, generando una constante fricción entre sus funciones productivas (asociadas al acopio de material tóxico para la salud humana) y la creciente vida urbana en la llamada capital mundial del cobre. A partir de un conjunto de antecedentes y experiencias que antes han intentado transformar la relación del puerto con la ciudad, el presente artículo explora cómo dichas ideas pueden ser reaplicadas al contexto actual. La investigación posee una virtud procedimental al introducir el método de la utopía concreta (Lefebvre, 1970) para para organizar y sistematizar propuestas de diseño urbano, junto a abrir el debate sobre el rol del puerto de Antofagasta y como resolver sus conflictos desde las disciplinas urbanísticas, necesitando para ello, de transformaciones institucionales que empoderen el accionar de nivel local.

Palabras clave: Antofagasta, ciudad puerto, contaminación, diseño urbano, utopía concreta.

\begin{abstract}
This article introduces the method of the concrete utopia for exploring feasible alternatives to transform the port of Antofagasta. This urban infrastructure has been criticized because a series of socio-spatial problems related to its productive activities, especially regarding the storage of toxic materials near the downtown. Based on a series of documented experiences that has tried to transform the relationship between this port and the city, this article explores how these ideas may be reconsidered in the current context. Thus, on one hand, the article valorizes the concrete utopia for developing urban design proposals and on the other hand it discusses the critical role of Antofagasta's port within the urban tissue, aiming to provide arguments for debating about its future.
\end{abstract}

Keywords: Antofagasta, concrete utopia, pollution, port city, urban design.

* Filiación: Universidad Católica del Norte, Antofagasta, Chile. Contacto: francisco.vergara@ucn.cl

** Filiación: Universidad de Chile, Santiago, Chile. Contacto: atexido@uchilefau.cl

Cómo citar: Vergara-Perucich, J. y Texido, A. (2018). Hacia la utopía concreta: crítica y prospección para la Ciudad Puerto de Antofagasta, Chile. Revista de Urbanismo, 39, 1-24. https://doi.org/10.5354/0717-5051.2018.50800 


\section{Introducción}

La relación entre el puerto de Antofagasta y la ciudad ha llegado a ser altamente conflictiva dados los niveles de contaminación que emanan desde sus operaciones y su ubicación en el centro histórico de la ciudad. A esto, se suma que el diseño del puerto se ha tornado obsoleto, especialmente respecto a exigencias técnicas como ambientales. Es parte de las preocupaciones de la población antofagastina esta relación rota, considerando que se trata de una de las principales Ciudades Puerto del Pacífico, desde donde se exporta cerca del 30\% del cobre a nivel mundial (Phelps, Atienza, \& Arias, 2015). Desde una mirada crítica a esta infraestructura, se plantea una propuesta de transformación en base a un conjunto de antecedentes previamente desarrollados, recolectados para producir una imagen prospectiva del Puerto de Antofagasta y su relación contextual.

El presente artículo explora la metodología propuesta por Henri Lefebvre para los estudios urbanos conocida como la utopía concreta (Lefebvre, 1970), método de investigación que busca articular crítica académica con propuestas imaginativas y realizables, no solo dejando hablar a los datos recopilados desde el trabajo en terreno o de fuentes científicas certificadas, sino avanzar y atreverse a proponer. El objetivo de la utopía concreta no es generar verdades absolutas o teorías generales, sino disputar la ciudad con proyectos y propuestas que emergen desde el conocimiento, en la interacción propia que implica co-habitar el espacio. En este caso, la propuesta surge desde la urgencia de haber detectado en las actividades del puerto de Antofagasta la principal causa de la alta presencia de metales pesados en el centro de la ciudad. Sin más, se ha catalogado a Antofagasta como la ciudad con mayores niveles de concentración de Cobre, Arsénico, Zinc y Molibdeno a nivel mundial (Tapia, Orrego, Valde, Tchernitchin, Dorador, Bolados \& Harrod, 2018).

Se presenta inicialmente el origen del método de la utopía concreta a partir del trabajo de Henri Lefebvre. Luego, se explican los principales desafíos que enfrentan las ciudades puerto en el contexto global actual, buscando evolucionar y adecuarse a la era postindustrial, incorporando al diseño cambios demográficos para consolidarse como parte de los tejidos socio-espaciales, con claro aporte a la vida urbana. A partir de esta mirada, se expone el caso del Puerto de Antofagasta y su toxicidad, problematizando la importancia de aplicar en esta infraestructura urbana el método de la utopía concreta para ensayar posibles transformaciones. Finalmente, el artículo concluye con la construcción de la utopía concreta para el puerto de Antofagasta, en busca de abrir una discusión sobre el futuro de la ciudad a partir de una transformación radical en el puerto, tanto formal como funcional y de gestión, avanzando hacia un modelo más sostenible de Ciudad Puerto.

\section{La utopía concreta como exploración transformadora de la vida urbana}

¡Un utópico! ¿Y por qué no? Para mí ese término no tiene connotaciones peyorativas. Dado que yo no ratifico las obligaciones, las normas, las reglas y las regulaciones; o dado que yo pongo todo el énfasis en la adaptabilidad; que yo disputo la concepción de 'la realidad' y considerando que para mí incluso lo posible ya es en parte real. Yo, de hecho, soy un utópico...un militante de las posibilidades (Lefebvre, 1984, p. 192).

A ratos, la palabra utópico en urbanismo ha sido tratada de forma peyorativa al ser una disciplina que se ha alineado con las urgencias del tiempo actual $y$ ha renunciado, entre otras cosas, a teorizaciones más profundas sobre la forma urbana y el pensamiento urbanístico (Carmona, 2014; Cuthbert, 2011; Sorkin, 2009). Como ha sido planteado a causa de la desregulación neoliberal, el rol de los procesos de transformación y producción del espacio para mantener la hegemonía del modelo capitalista es fundamental, siendo servil a la acumulación por urbanización (Boano \& Vergara-Perucich, 2017; Harvey, 2008; Lefebvre, Martínez Gutiérrez y Martínez Lorea, 2013). En la frenética búsqueda por parte del capital para optimizar la obtención de ganancias -en lo posible inmediatas- a partir de procesos productivos como la urbanización, los espacios reflexivos y críticos son reducidos a su mínima expresión y, ciertamente, desplazados desde la práctica profesional, no siempre considerados desde la autoridad, confinados al espacio académico (Acuto, Parnell \& Seto, 2018; Eccles, Hamnett, Huxley \& McLoughlin, 1990; Patel, Greyling, Parnell \& Pirie, 2015). Así, la crítica propositiva se aleja de los espacios de toma de decisión. Talleres y cursos de 
arquitectura y urbanismo son, quizás, uno de los últimos bastiones de la utopía de una ciudad futura distinta a la actual, lugares donde aún el modelo neoliberal no ha permeado del todo la praxis urbanística (Pinder, 2015), demostrando el espacio creativo de la formación, pero también la dificultad de superar lenguajes crípticos y demostrar neutralidad y autonomía ideológica hacia el exterior de sus aulas.

No obstante, en el contexto chileno, esto se ve problematizado también por universidades exclusivamente profesionalizantes (Zurita, 2015), con escaso aporte cultural al medio (Sisto, 2017), asumiendo que los estudiantes deben producir algo que les sea útil después en el mundo profesional. En un círculo vicioso, no es raro ver que algunos docentes en escuelas de arquitectura también acuñen una mirada peyorativa a la exploración utópica de una ciudad distinta a la que se inscribe dentro de los marcos del libre mercado, incitando a los estudiantes a buscar modelos de ciudad factibles dentro de los márgenes neoliberales. Es importante discutir estas posturas: para Henri Lefebvre, la utopía es un ejercicio propio del urbanismo -y otras disciplinas proyectuales- que ofrece importantes posibilidades para reimaginar la sociedad con sus espacios $y$, ciertamente, clave para desconectar la vida cotidiana de los lastres del capitalismo. Existiendo una abundante crítica al desarrollo urbano bajo el modelo neoliberal (Gaudichaud, 2015; Miraftab, 2016; Monibot, 2016; Nuijten, Koster, \& De Vries, 2012; Vergara Perucich, 2018), existen escasas exploraciones post-neoliberales desde las disciplinas espaciales. La ciudad post-neoliberal del Chile que viene es plasmada en imágenes virtuales, en proyectos urbanos, pero avanza lentamente en planes maestros y aun es difusa en nuevas exploraciones normativas.

Sobre el desarrollo de alternativas post-capitalistas de ciudad, Lefebvre no sólo abraza la utopía como exploración necesaria para estos fines, sino que sugiere su utilización como una metodología para revolucionar los procesos urbanísticos (Purcell, 2013). Sin ir más lejos, el rol de las revistas especializadas chilenas de arquitectura y urbanismo para la implementación de los principios de la modernidad en Chile fueron claves para su éxito (Aguirre González, 2004; Fuentes Hernández, 2011; Mondragón y Téllez, 2006). El método que surge a partir de la utopía concreta se organiza en base preguntas que revisan las cualidades del espacio que más afectan a las personas en ciertos espacios sociales que habitan, anteponiendo a la exploración estética un cuestionamiento ético de las condiciones de la vida urbana bajo observación (Coleman, 2015). Esta exploración puede ser capaz de incorporar y adaptar experiencias similares ya iniciadas en contextos donde la sustentabilidad urbana ha sido ya asumida institucionalmente. Con una lógica similar a la del libre ejercicio académico, "una utopía experimental es la exploración de lo que es humanamente posible, basado en las imágenes e imaginarios sometidos constantemente a la crítica y referenciados a una problematización de lo real, entendido como mecanismo de retroalimentación proyectual" (Lefebvre, Kofman \& Lebas, 1996, p. 15). La idea de utopía concreta de Lefebvre (1961) fue reforzada para el derecho a la ciudad (Lefebvre, 1969), describiendo que este método sería clave para visualizar el futuro de una ciudad cuyos procesos de producción espacial sean democratizados y despojados de las ataduras del capitalismo. Luego, en el libro La revolución urbana (Lefebvre, 1972), la utopía concreta será mejor explicada como una investigación sobre los posibles futuros desde las limitaciones técnicas y sociales, contemplando las oportunidades reales existentes en una situación dada de la humanidad (Stanek, 2011).

En el tratamiento de la utopía para el pensamiento crítico, Lefebvre entrega continuidad al trabajo de Ernst Bloch en relación con producir algo que no es una fantasía político-social sino una construcción que alimenta de esperanza al pensamiento filosófico, basándose en raíces sobre lo deseable pero también en lo posible (Bloch, 1988). Así, Lefebvre también discute las utopías abstractas y en contraparte habla de las utopías concretas, entendidas como modelos de posibles desarrollos mediante hipótesis del espacio, que pretenden activar procesos dialécticos de disputa por imaginar el futuro de un espacio urbano en particular (Stanek, 2011). Este método incorpora otras dimensiones del problema urbano como la economía, las relaciones sociales, el paisaje y la política. La utopía concreta busca, entonces, abrir discusiones urbanísticas sin declarar absolutismos sobre propuestas espaciales sino dialécticamente invitar a otras miradas a discutir el futuro de la ciudad con propuestas sobre la mesa, pero también prospectando la vida urbana que se podría dar en dichas hipótesis espaciales, considerando los importantes avances que se 
están dando en nuevas tecnologías y herramientas de representación.

La utopía concreta, como modelo de exploración espacial, está fuertemente vinculada a la enseñanza de la arquitectura. Sin ir más lejos, en el caso chileno, la mayoría de los proyectos de titulación de las escuelas de arquitectura tienen una importante similitud con la idea de utopía experimental de Lefebvre; dado que identifican un problema urbano, analizan el entorno, generan un diagnóstico, iteran en su proceso y proyectan. Desde la descripción del método de la utopía concreta a su ejecución, se podrían describir los siguientes pasos:

1. Problematización social: Identificar un problema social relevante basado en datos científicos de fuentes multidisciplinarias.

2. Espacialidad del problema: Identificar la o las manifestaciones espaciales de dichos problemas.

3. Hipótesis de transformación: Explorar las soluciones al problema desde diferentes perspectivas multiescalares para construir una hipótesis de transformación, que intente equilibrar los diversos intereses detectados, considerando el análisis y adaptación de experiencias.

4. Evaluación futura: Evaluar los efectos socioespaciales de las transformaciones sugeridas, considerando ventajas y desventajas de la hipótesis.

5. Utopía concreta: Construir la utopía concreta y abrir una discusión proyectual en base a evidencias y argumentos robustos.

El principal aporte metodológico de la utopía concreta en el ámbito de las ciencias sociales está en la crítica acompañada de una espacialización y una consecuente prospección de los efectos que dicho proyecto tendría sobre la vida urbana, describiendo con mayores detalles los resultados positivos y negativos de la hipótesis, situando al autor de la propuesta en el futuro (espacio utópico) y revisando los modelos desarrollados.

En este artículo, se utiliza el método de la utopía concreta para construir un argumento urbanístico prospectivo que dispute la realidad actual del puerto de Antofagasta, a partir de su condición crítica actual. Para elaborar la hipótesis de transformación se revisan diversas propuestas proyectuales que se han realizado sobre este elemento urbano para -a partir de esas ideas que no se materializaron-, proponer una utopía concreta que abra un debate disciplinar. Como se ha expuesto, el puerto de Antofagasta tiene ya demostrada una nociva relación ambiental actual con la ciudad, dada su localización fundacional junto al centro histórico de la ciudad y la contaminación que ha emanado desde sus actividades (Tapia et al., 2018), principalmente por metales pesados, la que ha terminado afectando a los niños y habitantes de la ciudad (Colegio Médico de Chile, 2018). No obstante, exploraciones espaciales para su transformación son escasas. Es por esta razón, que se hace necesario un método de utopía concreta: para romper con las ataduras de la realidad presente -hiperneoliberalizada- y proponer una vida urbana distinta. Así, también, develar e instalar una discusión académica sobre el método de la utopía concreta en el campo disciplinar urbanístico chileno, reestableciendo el vínculo universidad-realidad.

\section{El Puerto de Antofagasta como infraestructura de alto impacto social}

La comuna de Antofagasta ha sido señalada como la capital minera de Chile, al ser el principal centro poblado y capital de la región donde se produce cerca del $28 \%$ del cobre a nivel nacional (Vergara-Perucich, 2018). A pesar de esta ventaja comparativa se puede evidenciar la existencia de un fallido modelo de desarrollo urbano sustentable, donde pese a liderar el ingreso per cápita del país, se configura sin mejores estándares urbanos o ambientales, como la ciudad principal de un enclave extractivo moderno (Arias, Atienza \& Cademartori, 2014; Daher, 2015). Diversos datos informan cómo este contradictorio modelo de desarrollo urbano se representa en las cifras: la región aporta un 9,3\% al producto interno bruto nacional (Banco Central, 2018) lo que la transforma en la segunda de mayor contribución al crecimiento económico de la nación, sólo detrás de Santiago que contribuye con el $46.3 \%$. Esto podría considerarse como meritorio dado que en Antofagasta sólo vive un 3,46\% de la población a nivel nacional, ocupando el noveno lugar en lo demográfico. Este dato es indicativo de que la riqueza de la región yace en su potencial extractivo a partir de un suelo rico. No obstante, a pesar de la riqueza de la región, en Antofagasta durante 2018 se ha registrado la mayor tasa de desempleo a nivel nacional, ponderando 10,9\%. Esto, a pesar de que el Indicador de Actividad Económica Regional registra una variación positiva de 15,2\% entre 
julio de 2017 y marzo de 2018 (INE, 2018). Como en el resto del país, la distribución desigual en la región entre desarrollo económico y beneficios sociales se ve representada en más de un indicador.

Una de las particularidades de la ciudad de Antofagasta es que en los últimos años ha presentado importantes dificultades en aumentar su población residente, a pesar de ser la comuna del país con el más alto ingreso per cápita (CASEN, 2015). Sin embargo, el Observatorio Laboral de la Región de Antofagasta (OLAB, 2018), indica que el $17,4 \%$ de los trabajadores (más de 55.000 personas en 2016) no viven en la región sino en otro lugar. Este efecto es más común en regiones dependientes de la extracción de recursos naturales caracterizado por un conjunto de externalidades negativas que desincentivan la migración de los trabajadores a los centros de empleo (Jamett y Paredes, 2013). Entre las hipótesis que manejan los investigadores de este fenómeno conocido como conmutación, está "la Región de Antofagasta se destaca como un lugar precario y poco atractivo para vivir y solo interesante por sus oportunidades laborales con ingresos altos." (Rodrigo y Atienza, 2014, p. 178). Esto implica, además, que se genera un círculo vicioso en que estos salarios que surgen de la actividad económica en la región a partir de, principalmente, la actividad minera, se consumen en gran parte en otras regiones, deslocalizando el ciclo económico entre una región explotada, como es Antofagasta, y otras regiones beneficiadas (Rehner \& Rodriguez, 2018). Sobre las causas de la conmutación, se manejan algunas hipótesis.

Dentro de los factores que inciden en el desarraigo y desincentivo para vivir en la ciudad aparece el costo de vida. Antofagasta se configura como una ciudad excesivamente cara para vivir, donde los hogares destinan en promedio un $53 \%$ de sus ingresos al pago por acceder a una vivienda, lo que se agrava en los sectores de menores ingreso de la población (Vergara-Perucich, 2018). Para tener una noción de lo crítico de esta situación, en ciudades de naciones miembros de la OCDE, los hogares destinan un promedio del $21 \%$ del ingreso por hogar al pago de arriendo (OECD, 2018). Esto podría ayudar a comprender el significativo aumento de campamentos en quebradas y laderas, que según TECHO entre 2007 y 2016 pasó de 632 hogares a 6.229 (TECHO, 2016). Siguiendo con el problema de la desigual distribución de oportunidades en la región, datos del Censo 2017 indican que en Antofagasta hay 12.233 viviendas sin ocupantes -en arriendo o deshabitadas- lo que contrasta con el hecho de que, seguramente, los hogares en campamentos bien podrían ser reacomodados en dichas unidades de vivienda ya disponibles y mejor consolidadas. El costo de vida en la ciudad de Antofagasta, en particular, no se condice con la calidad ambiental de la comuna. La contaminación en la ciudad es tan persistente que aún no ha sido resuelta: pese a la importante cantidad de estudios al respecto, evidencia de un miedo instalado, ya que los agentes contaminantes provenientes de la principal actividad productiva nacional causan daños a largo plazo, problema alojado en la memoria colectiva de los antofagastinos.

Según mediciones, entre 1958 y 1970 cerca de 300.000 habitantes estuvieron expuestos a altas concentraciones de arsénico en el agua de consumo diario (Borgoño y Greiber, 1971), lo que produjo una alta presencia de pacientes con cáncer a la vejiga y al pulmón (Smith, Goycolea, Haque \& Biggs, 1998). Las tecnologías han cambiado y a pesar de que la empresa de aguas publica sus estudios mostrando niveles de contaminación permitidos para consumo -y validados por el Ministerio de Salud-, la compra de dispensadores de agua potable en la ciudad se transformó en una práctica común. Por un lado, la riqueza del suelo es indiscutible gracias a la presencia de minerales estratégicos para el futuro económico de la nación, más lo que no ha sido resuelto es que su explotación se desarrolle con estándares socioambientales óptimos.

En el particular de la ciudad de Antofagasta, durante décadas el material extraído del suelo ha sido transportado a través de un trazado ferroviario que data de los orígenes de la ciudad y que cruza por su centro, con material altamente peligroso para la salud y acopiado en el puerto, generando un prolongado proceso de envenenamiento del área urbana (Sepúlveda, Vega y Delgado, 2000). El puerto de Antofagasta ha sido progresivamente impugnado por la ciudadanía, no obstante, su monofuncionalidad exportadora, escueta articulación con la trama urbana y el ser identificado como un foco contaminante de la ciudad hacen necesario que se piense en las posibilidades de reorganizar su formato productivo, sumado a una mirada territorial que 
comprenda los sistemas interconectados de

infraestructura vial, ferroviaria y portuaria disponibles.

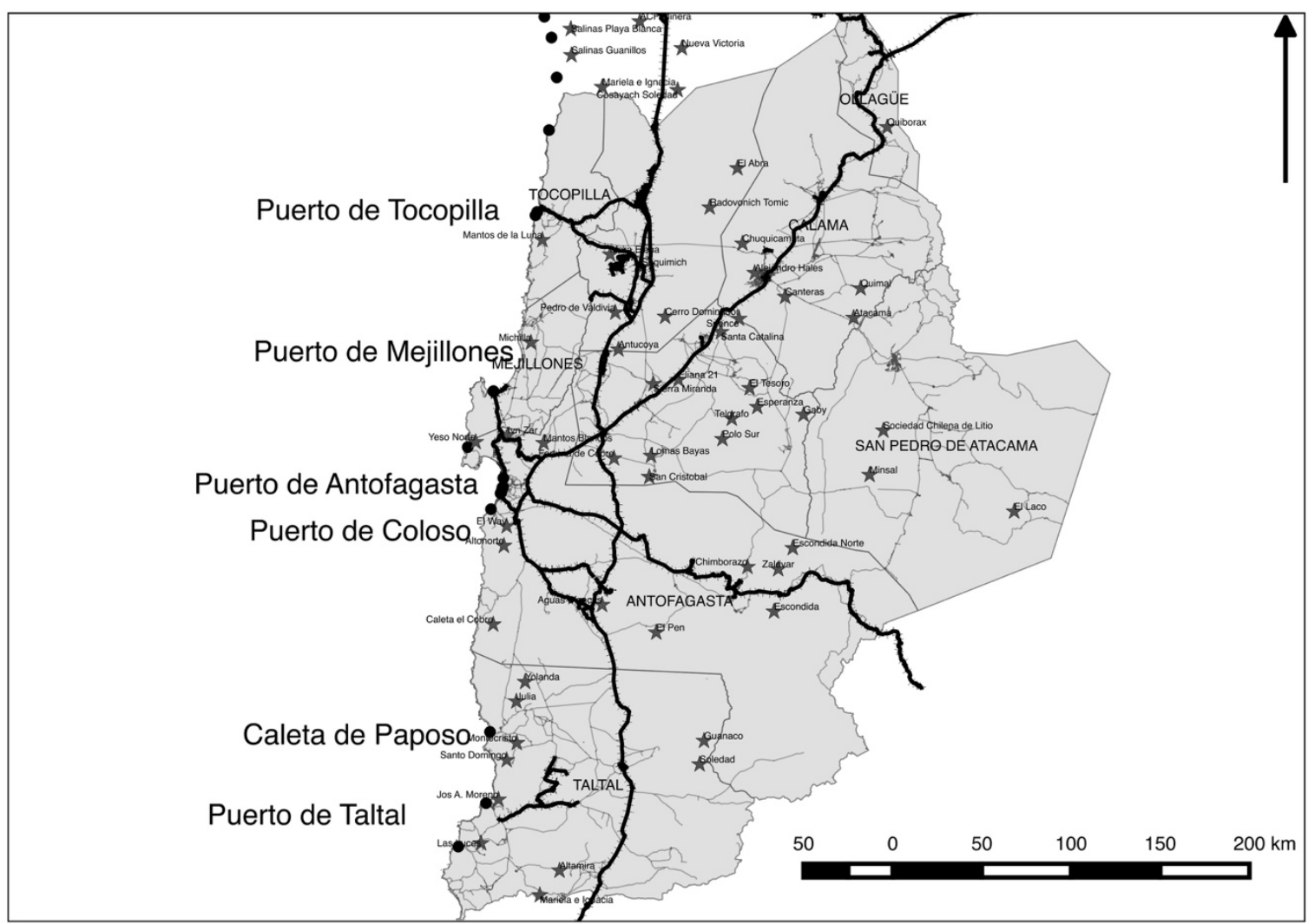

Figura 1. Red de puertos, líneas ferroviarias y faenas mineras en la Región de Antofagasta.

Fuente: Elaboración propia.

En el año 2014 y 2015, un conjunto de organizaciones sociales de la ciudad se reúne bajo el lema 'Este polvo te mata' para reclamar contra la presencia de metales pesados en el centro histórico de la ciudad de Antofagasta, atribuyendo dicha presencia a las emisiones propias del trasvasije que se desarrolló y desarrolla en el puerto de Antofagasta. El material también ingresa al puerto en camiones tolva cubiertos y contenedores. Una vez en el puerto, el concentrado de mineral se mantiene almacenado en un galpón por hasta 30 días (Antofagasta
Terminal Internacional S.A., 2005). No obstante, los galpones de acopio de material (Figura 2) no logran demostrar una hermeticidad segura desde la perspectiva sanitaria. Tampoco se ha demostrado su capacidad de resistir ante las repetidas marejadas o en caso de tsunami. Esto, porque existen antecedentes de tsunamis, como el ocurrido en 1877, que alcanzó el centro mismo de la ciudad en la plaza Colón. El conjunto urbano del puerto de Antofagasta, entonces, se presenta como un espacio conflictivo para la ciudad. 


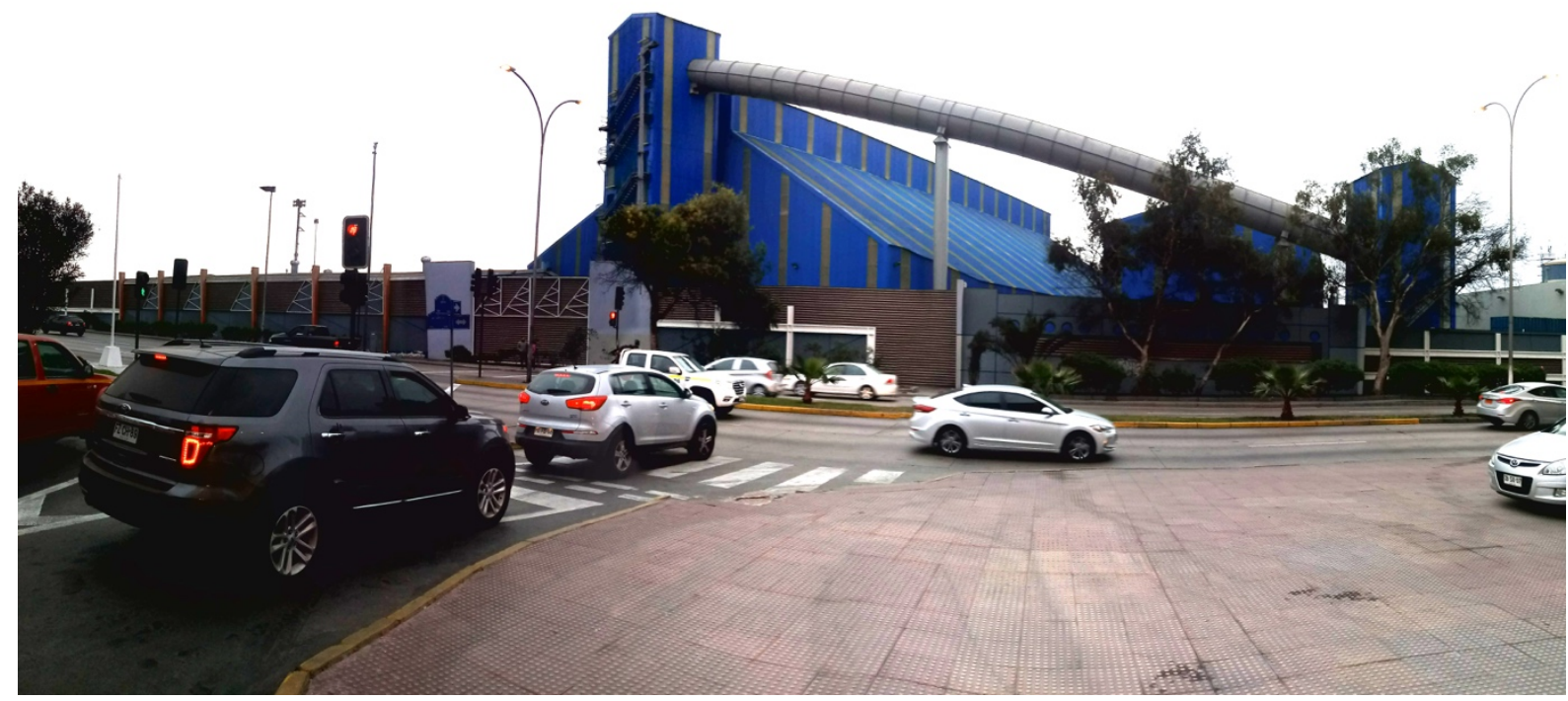

Figura 2. Galpón de almacenamiento de material mineral en el Puerto de Antofagasta y su relación con la calle.

Fuente: Elaboración propia.

Existe cierto consenso en la literatura de salud pública que la intoxicación humana por metales pesados tiene relación directa con el cáncer (Cogliano et al., 2011; Nawrot et al., 2006).

Esto se podría ver en Antofagasta, dónde entre el año 2000 y 2015 , se produjo un aumento del $42 \%$ en las defunciones a causa del cáncer, siendo ésta la principal causa de muerte en la región con un $29,4 \%$ del total (DEIS, 2016). El Colegio Médico de Chile ha solicitado reiteradamente que Antofagasta se declare zona saturada por contaminación, cuyo presidente regional, Dr. Aliro Bolados, planteaba en 2015: "Acá no sirven las mejoras, sino que eliminar definitivamente todas las fuentes de contaminación, como única solución para proteger la salud de la población" (Bolados, 2015). Un grupo de científicos de la Universidad de Antofagasta publicaron en la prestigiosa revista PeerJ un robusto conjunto de datos sobre la presencia de metales pesados en el centro histórico de la ciudad de Antofagasta, indicando que dichos contaminantes son producto de actividades humanas y que el principal foco sería el puerto de Antofagasta (Tapia et al. 2018).

Los resultados confirman una histórica relación de conflictos entre esta infraestructura y la ciudad. El estudio es claro en mencionar que las concentraciones de arsénico, cobre y zinc son los más altos a nivel mundial.
Los altos niveles de concentración afectan el desarrollo biológico infantil, haciendo que una exposición prolongada acelere las posibilidades de contraer cáncer a la vejiga y al pulmón hacia la adultez, configurando un envenenamiento lento y silencioso. También, en etapa de gestación, los contaminantes pueden producir alteraciones bioquímicas que generen fallas neuronales o sistémicas. También se pueden ver afectadas las capacidades reproductivas y el coeficiente intelectual. (Tapia et al. 2018, p. 15). Reciente evidencia indica una potencial causalidad entre la exposición a metales pesados y desarrollo de autismo en niños (Al-Farsi et al., 2013; De Soto \& Hitlan, 2010). Sin ir más lejos, luego de una serie de exámenes a los infantes que asistían a los centros de educación parvularia Semillita y Los Pollitos (ambos localizados dentro de un radio de $\mathbf{4 0 0}$ metros de distancia desde el puerto), los resultados indicaron que 107 niños tenían plomo y 45 arsénico en sus torrentes sanguíneos a niveles peligrosos (Valenzuela, 2014). El puerto de Antofagasta es una infraestructura disruptiva sobre la trama espacial por sus efectos socioambientales. Tanto el jardín infantil Semillita como Los Pollitos, fueron relocalizados y ahora se encuentran a más de 1 kilómetro de distancia desde el Puerto. ¿No debió ser al revés? ¿Será necesario en un futuro relocalizar la ciudad a $1 \mathrm{~km}$. de distancia del puerto? La solución espacial resulta tan llamativa como inquietante, donde se pone primero una 
infraestructura contaminante por sobre la vida urbana de la ciudad.

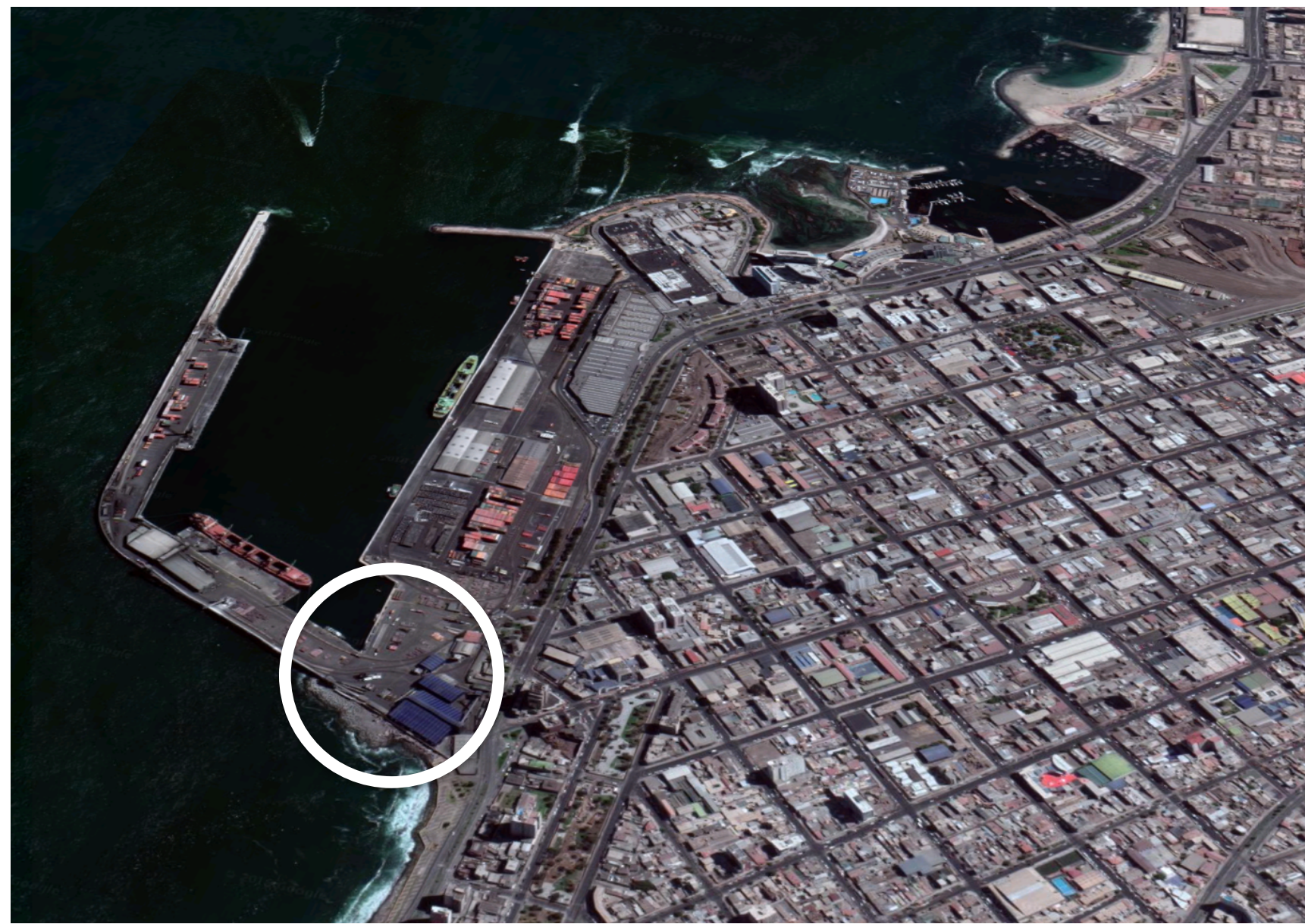

Figura 3. Vista aérea del puerto de Antofagasta y su contexto urbano. El galpón azul en la equina inferior del recinto portuario.

Fuente: Google Maps, 2018.

Finalmente, y como se ha expuesto, el puerto enfrenta un problema de alta magnitud dada la sismicidad chilena. Un tsunami podría convertir tanto a barcos como contenedores en proyectiles contra el centro histórico de la ciudad y el shopping mall ubicado al norte de las faenas portuarias (Figura 3). Este shopping mall, precisamente, resultó como parte de un proceso de cambio de uso de algunos predios del puerto, oportunidad perdida en proporción y porcentaje de uso de suelo de un espacio priorizado y destinado al consumo, en base a un volumen cerrado y que ha privilegiado la instalación de comercio nacional o global por sobre aportar a las mermadas economías locales. Por su parte, la experiencia de Chile y Japón en 2010 demuestra que no existen obras de contención efectivas capaces de soportar el embate de un tsunami. Como se muestra la carta de inundación (Figura 4) para la ciudad de Antofagasta (SHOA, 2013), en caso de golpear al puerto las olas llegarían hasta calle Matta, pleno centro histórico de la ciudad y uno de sus ejes comerciales, afectando de forma directa a cerca de 80 hectáreas, poniendo en riesgo a los usuarios habituales de este sector comercial y a los 10.000 residentes del sector (Instituto Nacional de Estadísticas (INE), 2018). Existen otros sectores de la comuna y región donde un puerto podría ofrecer mayor seguridad sanitaria y reducir el riesgo de desastres naturales. Existe una clara dificultad de un ente público a escala regional capaz de comprender y visualizar las conveniencias de un emplazamiento u otro, haciendo 
que la autorregulación se muestre como un mecanismo frustrado para infraestructuras contaminantes y de riesgo para la población. Existen alternativas: se reconoce el caso del puerto de Mejillones, creado en 1997 con el objetivo de ampliar la capacidad exportadora regional. Además del abrigo natural y suelo público disponible, se eligió dicha bahía porque las condiciones topográficas, batimétricas y de organización espacial permitían suponer que la contaminación por metales pesados respecto a vientos predominantes, mareas y tsunami no impactaría directamente a la población urbana.

Para subsanar estos peligros, es fundamental aplicar medidas que busquen, por un lado, mantener el importante rol económico que cumple este sistema portuario a nivel nacional, pero resguardando los intereses de la población y reduciendo los riesgos asociados al emplazamiento del puerto y sus funciones productivas actuales.

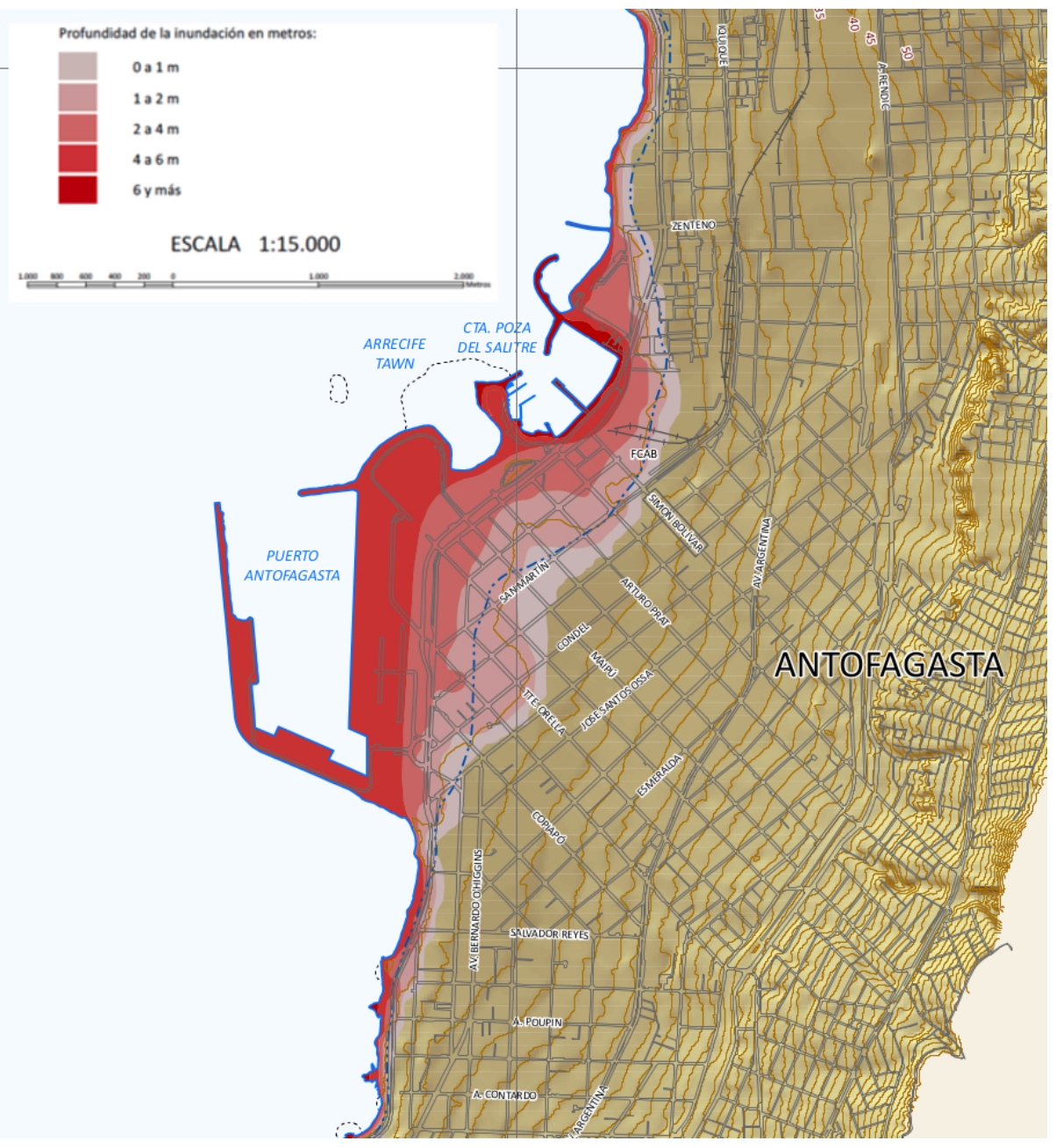

Figura 4: Carta de Inundación por Tsunami para el sector del puerto de Antofagasta en caso de Tsunami, 2013.

Fuente: Armada de Chile.

\section{Contexto: Idea de Ciudad Puerto en contradicción en Antofagasta}

El avance tecnológico en el diseño y dimensión de embarcaciones, los procesos de globalización de los mercados de bienes y la demanda por comercio internacional hacen que la magnitud de los nuevos puertos sea de una escala tal que se ha hecho compleja su disposición e interacción con áreas urbanas consolidadas. Por el contrario, dado que nuevas embarcaciones presentan hasta 400 metros de eslora, se tiende a reubicar nuevas áreas portuarias lejos de las ciudades. "Los puertos en Chile se generan por iniciativa privada, sin planificación 
estatal ni particular. Para nuevos terminales, rige la ley de la oferta y la demanda" (Ivelic Kusanovic, Miranda Zúñiga, Pastene Beitya, Chávez Gatica, y Vásquez Chávez, 2017, p. 99) planteamiento que intenta exponer la complejidad de un sistema portuario que desde 1997 optó por la asociatividad público-privada para la implementación y operación de infraestructura, debilitando la regulación y planificación desde el Estado (Ley $\mathrm{N}^{\circ}$ 19541, 1997). El objetivo estaba en la rentabilidad -lo que se logró de buena manera (Carrillo y Santander, 2005), pero se dejó de lado la sostenibilidad de sus diseños. Desde la década de 1970, con el cambio de paradigma del caso Baltimore (Gordon, 2001), las experiencias internacionales de reconversión de espacios portuarios obsoletos han tendido a disociar las actividades productivas intensivas de los puertos desde sus ubicaciones urbanas históricas. Si bien el comercio internacional se ha intensificado (lo que ha demandado una ampliación progresiva de áreas portuarias) el proceso de transformación demográfica de las ciudades ha densificado los centros urbanos y en ese contexto, actividades de alta intensidad productiva son preferiblemente reubicadas para no interferir en la vida urbana de las ciudades (Garcia, 2008; Giovinazzi \& Moretti, 2010; Sieber, 1991). Por otro lado, el fenómeno de las ciudades puerto las ha convertido en expresión de cambio de época en materia de planificación territorial, diseño urbano, innovación e incorporación de tecnologías, buscando hacer de los espacios portuarios preexistentes reservas históricas de la memoria cultural de dichas ciudades, generalmente con privilegio de la restauración patrimonial y espacios públicos, a la vez que la contaminación y externalidades negativas de las nuevas extensiones portuarias se irían relocalizando en otros lugares (Giovinazzi \& Moretti, 2010).

La revitalización de los frentes marítimos en ciudades puerto ha ido reconociendo procesos globales que pasaron de evaluar únicamente la productividad y eficiencia de las instalaciones a considerar los factores ambientales, generando mecanismos capaces de reconciliar los diferentes intereses, objetivos e influencias involucradas en los procesos de adaptación de puertos al siglo XXI, en que el antiguo puerto actúa como un espacio de re-encuentro entre la ciudad y el mar (Hoyle, 2010). La incorporación de los actores locales al proceso de transformación del puerto es una oportunidad para usar el proceso de modificaciones espaciales sobre una infraestructura productiva como un catalizador de instancias democráticas y de resignificación cultural a otra escala (Sieber, 1991). En este aspecto, es vital el liderazgo que puede ejercer la autoridad local democráticamente elegida para propender a un proceso de regeneración urbana armoniosa, que facilite la configuración espacial y administrativa de lo que se conoce como Ciudad Puerto. El proceso de adecuar las ciudades puerto para los desafíos actuales se vería entorpecido ante un liderazgo político débil (o fragmentado) que no permita articular los intereses de las actividades productivas dependientes del puerto y la comunidad urbana (García, 2008). Como menciona Pedro Ressano García (2008), los casos exitosos de reconfiguraciones urbanas en ciudades puerto se acompañan por proyectos de espacios públicos, parques, servicios con cualidades arquitectónicas y urbanísticas que terminan siendo un gran aporte a la vida urbana, tanto por su nueva calidad espacial como por una relevante posibilidad de diversificación económica. Al respecto, existen algunos consensos internacionales que se han logrado en cuanto a pensar las nuevas configuraciones de ciudades puerto en el mundo. Así, la organización mediterránea Citta d 'Acqua (Venecia), avalada por la Asociación para la Colaboración entre Puertos y Ciudades RETE, realizó un ejercicio multidisciplinar tendiente a definir 10 principios para repensar las ciudades con frente marino (Cittá D’Acqua, 2000):

1. Asegurar la calidad del agua y el medio ambiente.

2. Incorporar al diseño los tejidos urbanos preexistentes por lo que se deben integrar mutuamente.

3. La identidad histórica entre la ciudad y el frente marino es parte de su carácter

4. Se debe priorizar el uso mixto, incorporando instalaciones culturales, comerciales y viviendas.

5. Se debe asegurar el público acceso a los puertos.

6. La planificación de iniciativas público-privadas puede acelerar la implementación de transformaciones espaciales.

7. El estado debe asegurar la sustentabilidad de los proyectos de transformación.

8. Los frentes marinos son proyectos a largo plazo y pertenecen a la ciudad como un todo. 
9. La revitalización portuaria es un proceso abierto, adaptable a nuevas demandas y reparable a potenciales cambios en prioridades.

10. Los frentes marítimos deben estar abiertos al mercado internacional tanto en sus funciones como en el mismo proceso de rediseñarlos. (Giovinazzi \& Moretti, 2010).

Es importante entender que una transformación en un frente marino es un proceso que afecta a territorios y no solo a las ciudades, razón por la cual estas transformaciones se pueden pensar a otra escala, no solo en los márgenes de los límites urbanos sino a nivel regional o incluso a nivel de conectividades transnacionales. Sin embargo, es vital asumir que estas transformaciones no sólo obedecen a un pujante mercado mundial de bienes e infraestructuras sino también a un conjunto de demandas sociales propias de las ciudades que deben adaptarse y regenerar nuevas condiciones sustentables para la vida urbana contemporánea, algo que en el caso del Puerto de Antofagasta merece ser revisitado.
En general en Chile, la relación de los puertos y las ciudades presenta patrones comunes de conflicto a nivel nacional que han sido criticados escasamente por la literatura urbanística, y la mayor parte de esa crítica se ha desarrollado para el caso de Valparaíso (Alarcón, 2009; Ivelic Kusanovic et al., 2017) o Talcahuano (Alarcón, 2016). La literatura especializada que ha estudiado el problema urbano del caso de Antofagasta se ha enfocado en problemas más territoriales (Pérez, 2014; Thodes, 2016) que en casos específicos de sus dispositivos urbanos problemáticos como el puerto. En la práctica, las ciudades puerto se han discutido en espacios de decisión restringidos institucionalmente, privilegiando miradas más bien económicas dónde predominan los ingenieros civiles e inversionistas. Dentro de la poca literatura existente en Chile, se pueden identificar seis grandes barreras que impiden la articulación efectiva entre los puertos y sus ciudades, o bien, entre el frente costero y su correcta integración a la vida urbana en la producción armónica de lo que se puede entender como Ciudad Puerto. En la tabla 1, para cada problema, se insinúa una potencial solución para el caso del Puerto de Antofagasta. 
Tabla 1

Barreras y soluciones para ciudad-puerto inclusivas.

\title{
Barrera
}

1. Una tuición a la deriva: La modernización portuaria concesionó los frentes de atraque a operadores privados controlados por el Estado y la Armada, ajenos al control municipal. También se diluyó la capacidad planificadora entre el Ministerio de Obras Publicas que ejerce un control técnico del diseño de obras civiles de los puertos, el Ministerio de Transportes que focaliza en los impactos viales de las áreas portuarias y el Ministerio de Bienes Nacionales que con la DIRECTEMAR definen la gestión del suelo de los bordes costeros para eventuales expansiones.

\begin{abstract}
2. Niebla mono-funcional, timón neoliberal: El resultado de la neoliberalización de la administración de las ciudades intentó generar un modelo aparentemente auto-regulado, ineficiente para los objetivos inclusivos de las ciudades contemporáneas. En la optimización neoliberal del capital, los puertos se tienden a expandir para aumentar productividad y no para articularse ni entre ellos ni con el entorno urbano. La neoliberalización, entonces, aumenta la incompatibilidad del puerto con la trama urbana.

3. Puertos OCDE: A pesar de la importancia del cambio que implicó esta incorporación de Chile a este influyente grupo de naciones, las ciudades (en especial en regiones), la institucionalidad no ha logrado adecuarse a los nuevos estándares internacionales sobre instrumentos de planificación urbana, métodos de diseño urbano y exigencias sobre la calidad de vida en ciudades.
\end{abstract}

4. Nuevo zarpe hacia la experiencia internacional: Se tiende a citar los casos de Barcelona, Baltimore o Marsella, pero luego se descartan por la distancia cultural y, principalmente, económica entre dichas naciones. Experiencias más cercanas, como Medellín, Buenos Aires o Guayaquil, ponen el acento en la creación de una autonomía presupuestaria local e innovación administrativa para el desarrollo de las ciudades puerto.

5. Alternativas Ciudad-Puerto por la borda: La urgencia del capital y la búsqueda de renta e inversión a corto plazo ha impedido el desarrollo de una instancia reflexiva que permita articular de una mejor manera posible el proceso de diseño urbano de una transformación de un puerto en una ciudad, para producir una Ciudad Puerto.

Fuente: Elaboración de los autores extraído desde "Las barreras institucionales que dificultan la inclusión de Valparaíso ciudad puerto (Texido, A. y De La Sotta, P., 2014).

Este segundo paso de avance hacia la utopía concreta ha permitido complementar la problematización social del Puerto de Antofagasta con sus obstáculos espaciales e institucionales, ilustrando cómo las tendencias internacionales permiten abrir el debate sobre la
Transformación propuesta

Consejo de Coordinación Ciudad Puerto: Cambio administrativo para la implementación de Planes Integrales de Compatibilización Ciudad Puerto, generando una mesa de coordinación intersectorial y trans-institucional, establecida por la Ley 19.542 de 1997 pero aún en proceso de implementación.

Licitaciones que favorezcan diseños compensatorios: Se propone incorporar renovaciones que promuevan la apertura de los puertos a los entornos urbanos desde una mirada multidisciplinar, a partir de visiones consensuadas que se sean incorporados a los Planes Integrales de Compatibilización Ciudad Puerto. La validación de Concursos Públicos de Arquitectura y Urbanismo también surge como alternativa pertinente.

Asumir los compromisos de Chile con instituciones globales: En el caso señalado, se habla principalmente de la relación entre Valparaíso, el nombramiento de Patrimonio de la Humanidad por UNESCO y las falencias institucionales en gestionar dicha relación, viendo este nombramiento como un simple reconocimiento y no como una responsabilidad permanente de rescatar el tejido espacial y cultural que mereció la declaratoria del 2003. Esto debe servir de antecedente para otros puertos.

Avanzar hacia la autogestión del territorio: Capturar parte de las utilidades de las privatizaciones del agua, electricidad y alcantarillado en los municipios de las ciudades puerto para invertir en el mejoramiento de la relación Ciudad Puerto, para así potenciar los aspectos urbanos que se ven mermados por las externalidades negativas de las actividades portuarias.

Pausa reflexiva: Creación de una mesa técnica para el desarrollo de un plan maestro de transformación portuaria que revise los contratos existentes, obras en marcha e ideas a futuro, apuntando a romper con un borde costero privatizado y excluyente entre la ciudad y su respectivo borde y puerto.

pertinencia de esta infraestructura urbana, dada su comprobada relación conflictiva con la vida urbana de la ciudad. Hacia una utopía concreta, se asienta el punto que el objeto de transformación, el Puerto de Antofagasta, cumple con ser un problema social y espacial que necesita 
reflexiones prospectivas, las cuales se elaboran en el siguiente apartado.

\section{Hipótesis de transformación: El Puerto de Antofagasta y sus prospecciones}

Siguiendo con el método de la utopía concreta, en esta sección se revisan y organizan algunas propuestas previamente desarrolladas por otros especialistas para el puerto de Antofagasta y configurar así una hipótesis. Esto, más que una revisión de literatura, es una revisión de proyectos previamente desarrollados para interpretarlos hacia una nueva forma urbana para el puerto. Para esto, se ha realizado una búsqueda exhaustiva desde el año 1995 en adelante. Esta búsqueda se ha realizado principalmente mediante las bases de datos Cybertesis, Scopus, Web of Science y Scielo. Las propuestas de transformación espacial para el puerto de Antofagasta publicadas son escasas. También se hizo una búsqueda en el portal Mercado Público desde el año 2005 en adelante para revisar licitaciones, pero no se encontraron propuestas significativas de diseño urbano para el sector.
Finalmente, se revisaron proyectos para el Puerto de Antofagasta que se han presentado en el Servicio de Evaluación Ambiental y sólo se encontró el galpón de acopio que no es una utopía dado que se encuentra construido y en operación. De la búsqueda, entonces, se han excluido los proyectos que proponen únicamente un cambio en el borde costero, dado que en su mayoría no incluyen al puerto a dichas transformaciones. Dentro de estas exclusiones cabe destacar las propuestas de Teodoro Fernández para el concurso del borde costero elaborado por Creo Antofagasta (2017) -cuyas bases técnicas no consideraban el tramo costero central del puerto- y la remodelación del sector Balneario Municipal y Parque Croacia, de Humberto Eliash (2002), ambos anteproyectos materialmente desarrollados o en proceso, pero sin tocar el paño urbano del puerto.

Del total de proyectos revisados que se han orientado a transformar la relación entre el Puerto de Antofagasta y la ciudad, se han seleccionado las hipótesis de transformación que surgen desde cuatro propuestas en particular, los cuales se presentan a continuación.

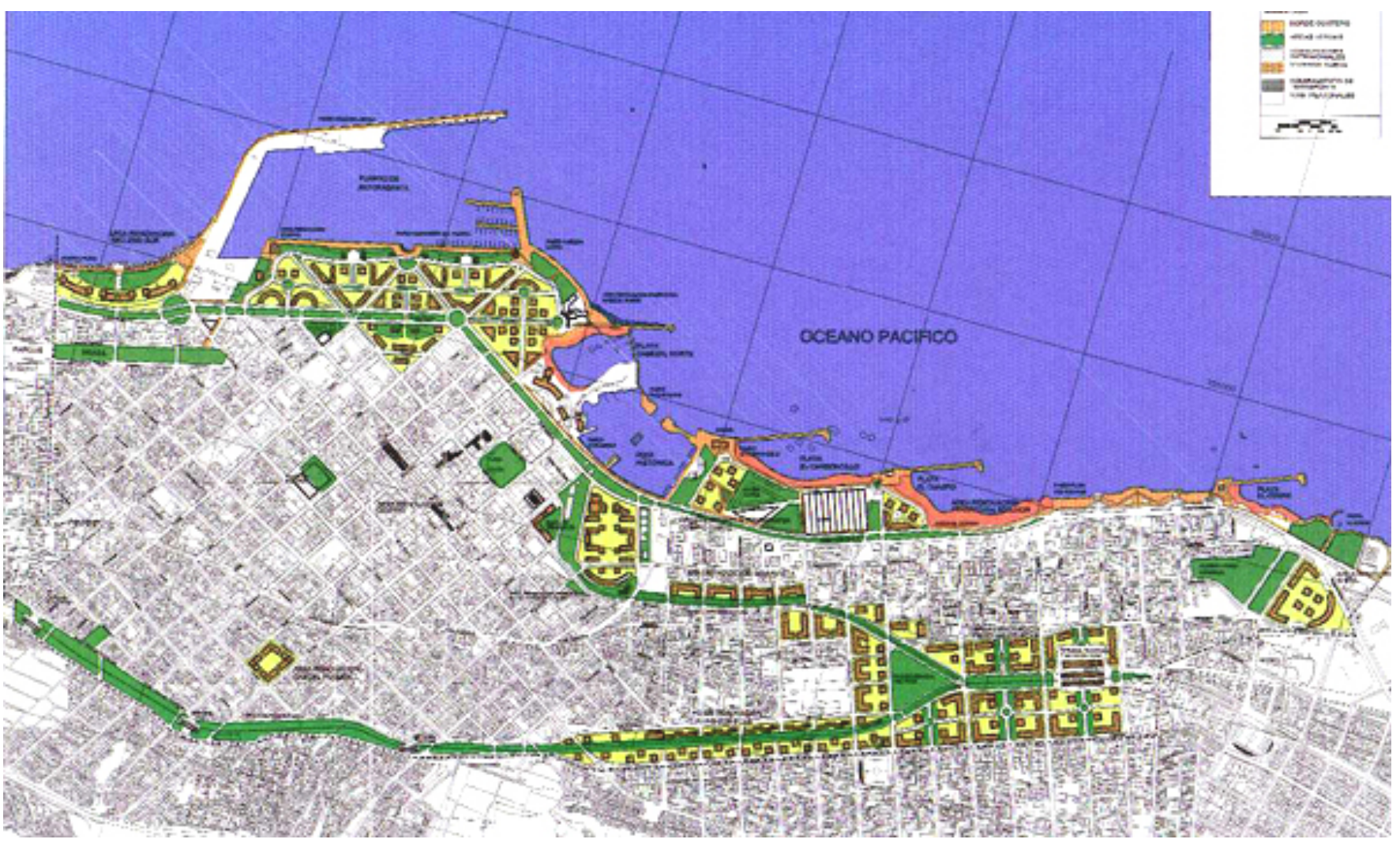

Figura 5. Plan seccional casco central y borde costero de Antofagasta, Dirección Ejecutiva de Obras Bicentenario.

Fuente: http://www.gubbinsarquitectos.cl/urbanismo_pages/pages/antofagasta/antofagasta.htm 


\section{La apertura del puerto hacia la ciudad}

En 1998, en el contexto de los preparativos para el Bicentenario de la Nación, el Gobierno Regional, el Ministerio de Obras Públicas y la Municipalidad contratan al premio Nacional de Arquitectura, Víctor Gubbins, para realizar un plan de transformación urbana para Antofagasta (Figura 5), con foco en el borde costero en su área central. La oficina desarrolla un plan seccional, incorporando un cambio significativo en la articulación del puerto con el tejido urbano. La propuesta busca hacer del borde costero el principal espacio público de la ciudad, configurar el centro como un mall abierto (similar al caso de Liverpool One en la ciudad británica) y aumentar las áreas verdes. Entre los objetivos de la propuesta de
Gubbins, se contaba la incorporación de terrenos del Ferrocarril Antofagasta Bolivia y el Puerto de Antofagasta al tejido urbano, además de tener a la vista la creación de un nuevo puerto minero alternativo y conectado en Mejillones. Desde este Plan Gubbins se puede sacar una primera idea coherente y a escala urbana de una potencial intervención en el puerto en base a su apertura y transformación programática. Los aportes de este plan, en parte, se han ido implementado como con la Costanera Central. Esta mirada más global propuesta por el Plan Gubbins que invita a discutir sobre la estratégica posición urbana del suelo del puerto, se buscó otras hipótesis proyectuales que asumiendo la apertura del puerto contribuyeran con la transformación de Antofagasta desde el puerto.

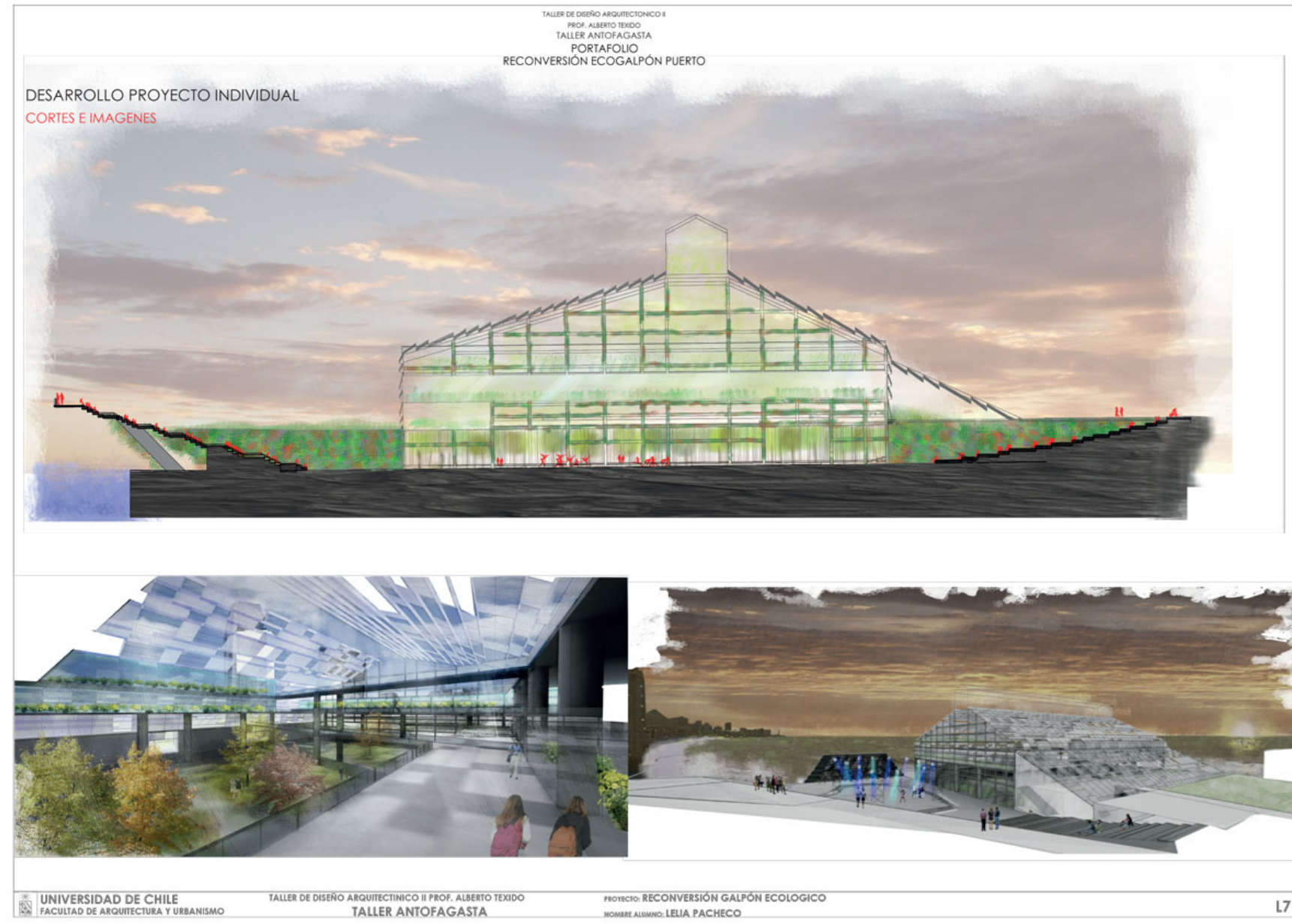

Figura 6. Reconversión del galpón de acopio y trasvasije en Eco-galpón, desarrollado por Leila Pacheco, Taller Ciudad Puerto FAU, Universidad de Chile, 2014. Fuente: https://proceso.uchilefau.cl/2014/project/reconversion-eco-galpon-puerto/ 


\section{Reconversión programática de arquitectura portuaria industrial}

Desde el Taller Ciudad Puerto de la Universidad de Chile se propuso en 2014 una transformación radical del galpón principal del Puerto de Antofagasta (Figura 6). Este galpón se construyó para reducir las emisiones contaminantes producto del trasvasije de material en el puerto, sin embargo y como ya se ha expuesto, su eficacia ha sido cuestionada. Habiendo detectado esto, la propuesta de Leila Pacheco buscaba aprovechar la estructura soportante para generar un espacio controlado de cultivo vegetal, en parte, como una declaración dialéctica por activar una disputa radical por ese espacio, a través de un proyecto urbano, que además abría los límites del recinto incorporándolo al espacio público costero. En este caso, se buscaba modificar la lógica contaminante para darle al galpón una connotación alimenticia, pasando de ser un foco de toxicidad a un foco nutricional, cubriendo parte de la demanda de hortalizas hasta entonces importadas desde otras latitudes.

\section{El Puerto como foco emisor de eficiencia energética a escala urbana}

Otro aspecto relevante en la ciudad de Antofagasta es la generación de energía. Presentando uno de los costos energéticos más altos entre las capitales regionales (Riveros, 2015), la sostenibilidad de las propuestas de transformación urbana debe adecuarse a esta realidad, en que además la mantención pueda considerarse desde el comienzo de las propuestas. En este caso, el arquitecto Rodolfo Ugarte (2010) destacaba la condición rocosa del borde costero público de Antofagasta (Figura 7), de características idóneas para la instalación de generadores de energía mareomotriz. Ugarte en su proyecto de título, proponía una renovación del paseo costero compuesto por piscinas de agua marina, conformadas por diques que traerían incorporados mecanismos de energía hundimotriz y mareomotriz, logrando la dualidad de un equipamiento recreativo con capacidad de generar electricidad y autofinanciamiento. 

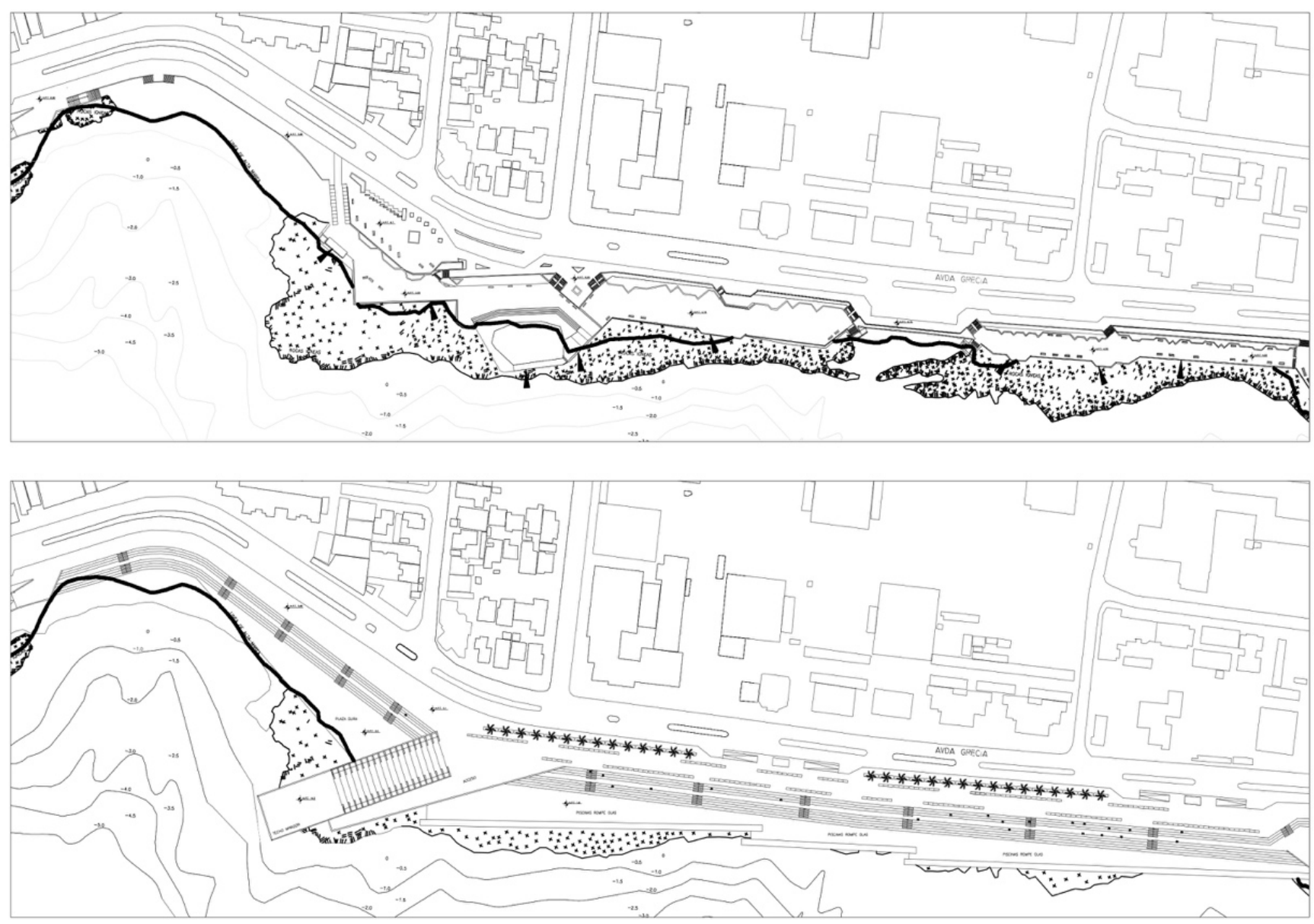

Figura 7. Proyecto de Título Teatro del Mar, desarrollado por Rodolfo Ugarte, FAU, Universidad de Chile, 2010.

Fuente: http://www.tesis.uchile.cl/tesis/uchile/2010/aq-ugarte_r/html/index-frames.html

\section{Puerto de Mejillones}

Una propuesta reciente ha reactivado la idea de trasladar el puerto productivo industrial desde Antofagasta al Puerto de Mejillones, a 60 kilómetros hacia el norte. Esta propuesta fue realizada por el Taller Ciudad Puerto de Mejillones (Figura 8), gestada en la Universidad de Chile durante 2017 y premiada por el Concurso Universitario de Ideas Transformacionales, como parte del Foro Latinoamericano de Infraestructura 2018, y que plantea soluciones urbanas para el sistema portuario regional, aumentando los estándares urbanos a través de la compatibilización de actividades productivas, la amortiguación a través del espacios públicos, la remediación ambiental y la adaptación al cambio climático, creando elementos de protección y reubicando equipamientos críticos en zonas menos expuestas a la inundación Tsunami, todas acciones posibles desde un vínculo urbano-industrial colaborativo. 


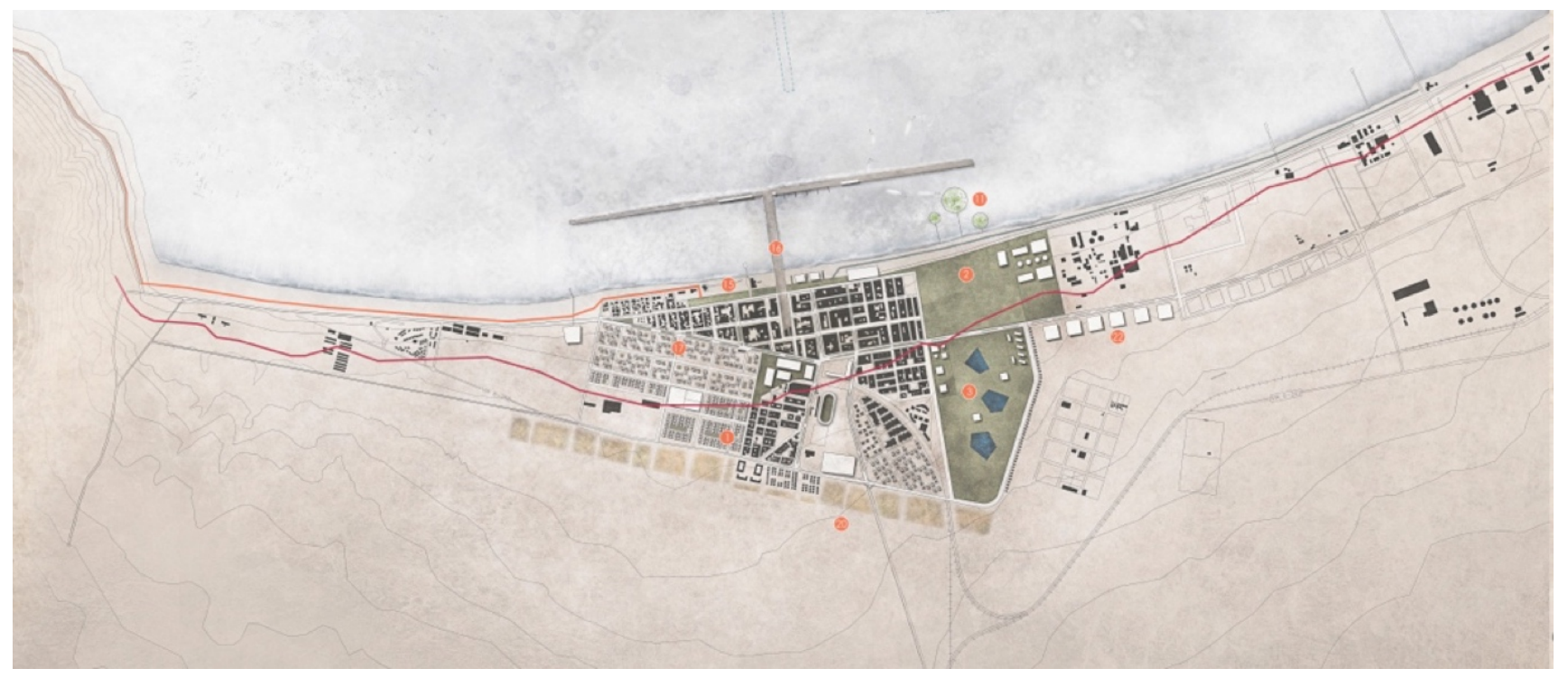

Figura 8: Plan Maestro Mejillones in_SEGURO, desarrollado por el Taller Ciudad Puerto FAU, Universidad de Chile, 2017.

Fuente: Archivo Académico Taller Ciudad Puerto FAU, Prof. A.Texido.

Este conjunto de hipótesis permite configurar un conjunto de prospectos que entregan un panorama futuro para la ciudad de Antofagasta que necesita ser evaluado con relación a sus alcances.

\section{Discusión: Ciudad Puerto de Antofagasta}

Las hipótesis de transformación expuestas permiten perfilar una utopía concreta para la ciudad de Antofagasta, en que se revierte la condición tóxica del puerto actual para convertirlo en un espacio de oportunidades para mejorar la calidad de la vida urbana de la capital minera mundial en una producción de una Ciudad Puerto con altos estándares. Siguiendo con la propuesta de la utopía concreta, corresponde evaluar los alcances que tendrían estas hipótesis con su eventual implementación.

Desde el Plan Gubbins, se asume la apertura de los paños del puerto y las áreas industriales aledañas, agregando a la ciudad un total de 22,3 ha de terreno. Esto permitiría el desarrollo de vivienda y equipamiento, a la vez que el puerto transformaría sus funciones. En esta nueva superficie disponible, basados en un coeficiente de ocupación del 0,4 y un coeficiente de constructibilidad de 2 podría entregar una total de 4.750 unidades de vivienda y/o oficinas, con esquemas apropiados a los actuales modelos de desarrollo urbano social integrado, promoviendo así una incorporación al casco histórico de familias postergadas por el mercado. Se podrían desarrollar conjuntos edilicios de 5 pisos, preservándose un primer nivel para uso mixto y desarrollo de espacios públicos de calidad, ubicados en una zona consolidada de la ciudad, diseñando vías de evacuación óptimas, junto con un plan para limpiar los residuos tóxicos presentes en el puerto. Con esta intervención, se aportaría a la reducción en un $35 \%$ del actual déficit cuantitativo de vivienda en la comuna, que según el Observatorio Urbano del Ministerio de Vivienda y Urbanismo asciende a 13.401 unidades (MINVU, 2018). No obstante, el abrupto incremento de oferta de vivienda en el centro de la ciudad podría, también, aumentar el precio de estas unidades por lo que además de la producción de vivienda se necesitaría una regulación que evite la especulación. La apertura del paño urbano en cuestión y la eventual construcción de estas viviendas podrían ayudar a aumentar la cantidad de áreas verdes en la ciudad, que en la actualidad es de aumento de áreas verdes. Según un estudio de 2017 elaborado por el Centro de Políticas Públicas de la Universidad Católica (Cea, Mora, Innocenti y Correa, 2017), la ciudad de Antofagasta presenta la menor accesibilidad a áreas verdes, caracterizada por que un $28,8 \%$ vive sin áreas verdes. Esto, sumado a que la ciudad solo cuenta con $1,3 \mathrm{~m}^{2}$ por habitante. La intervención a partir de la apertura del Puerto podría aumentar este 
factor, pasando desde cerca de 50 ha de áreas verde en la ciudad a 58 ha.

Desde la propuesta de Leila Pacheco, confinada al galpón de acopio principalmente, se ensaya la posibilidad de generar una reconversión del patrimonio histórico del puerto, rescatando infraestructuras en desuso y otorgándoles un valor programático necesario para la comuna. Retomando la idea de Pacheco, otro valor posible es la generación de un nuevo centro de intercambio comercial más asequible. Esta idea podría materializarse en la nueva vega central de la ciudad, la cual fue siniestrada por un incendio durante el mes de junio de 2018 y cuya ubicación original dificulta su accesibilidad.

La propuesta de Ugarte no solo hace hincapié en la energía proveniente del mar, sino pone el acento en el problema de los costos de la energía en la ciudad de Antofagasta, siendo una de las ciudades de Chile con mejor posibilidad de captación energética por fuentes solares y marinas. En este sentido, el Puerto de Antofagasta podría seguir operando como una infraestructura de alta relevancia a nivel urbano, no solo en la recepción de transporte marítimo no contaminante sino también como catalizador de energía eléctrica a partir de fuentes renovable no convencionales como puede ser la fotovoltaica, eólica y mareomotriz.

Un sistema de transportes regionales integrado, con un metro que una Antofagasta con Mejillones podría servir para optimizar la relación entre el puerto de Mejillones (con mejor batimetría y envergadura) y la capital regional. Así, los planes de potenciar el puerto de Mejillones tendrían mayor efectividad en base a generar una mejor conectividad entre ambas ciudades, facilitando que trabajadores del Puerto de Antofagasta sigan sus labores en Mejillones sin tener que abandonar su ciudad actual. Mejillones es una ciudad que enfrenta importantes problemas ambientales y sociales, por lo que un puerto de alto estándar podría servir para aumentar su dinámica económica interna y fortalecer su vida urbana, resolviendo las dicotomías actuales. Más aun, considerando que en los próximos años el corredor bioceánico entre Brasil y Chile buscará una salida al mar por esta región.

Además, indagan sobre una extraviada capacidad de comprensión territorial, denotando los efectos de la falta de una adecuada planificación preventiva junto a una desregulación monopólica, en cuanto a comprender y evitar los impactos negativos de la integración vertical de empresas productivas de alta incidencia socio-espacial, las instalaciones infraestructurales esenciales y los topes para ampliar la participación en el mercado de nuevos actores; situaciones que no han sido profundizadas en este texto, pero que abren nuevos espacios para discutir el rol de las infraestructuras costeras y portuarias en contextos neoliberales. 


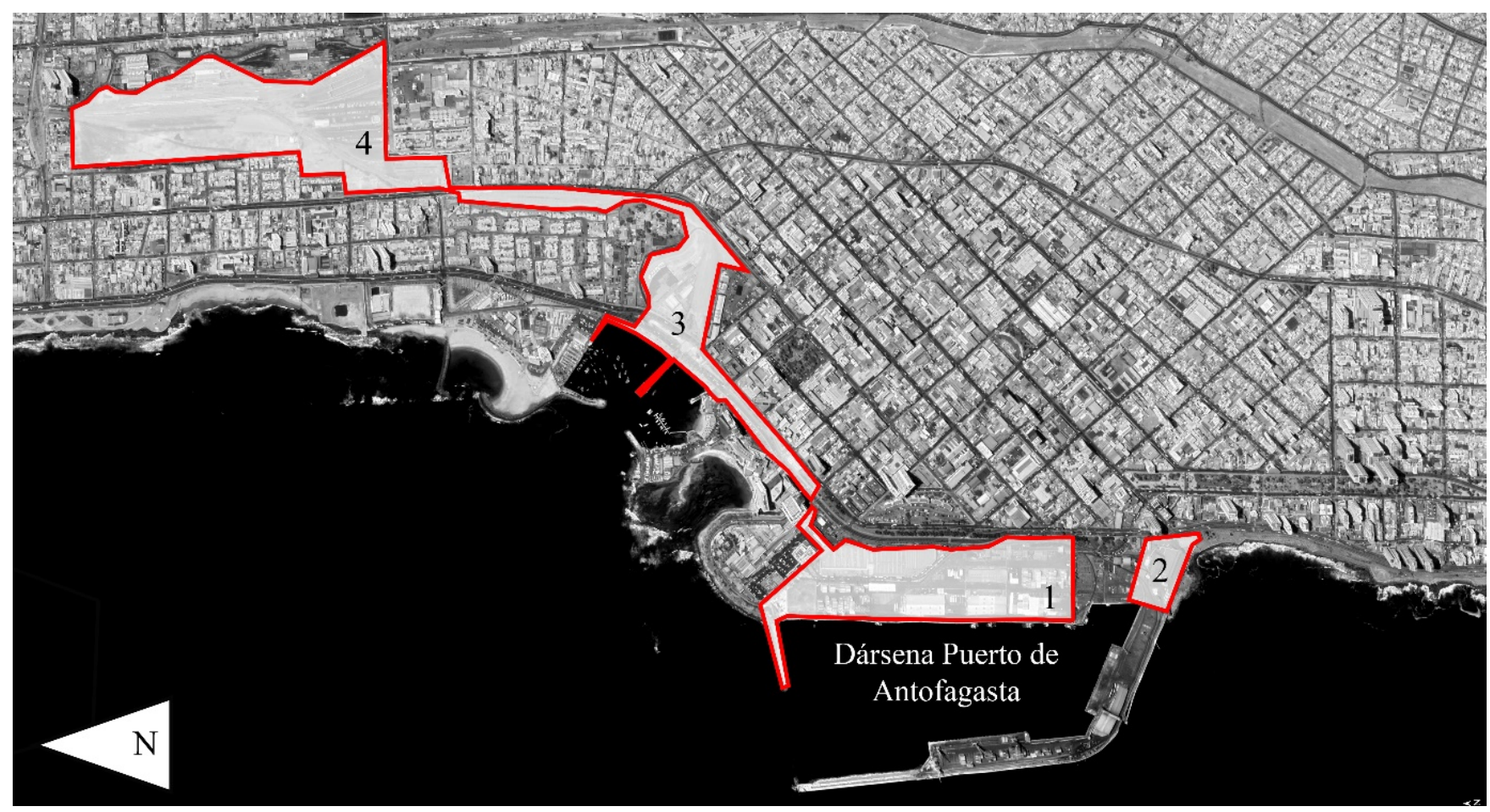

Figura 9. El mapa representa los principales espacios de transformación de esta utopía concreta de la Ciudad Puerto de Antofagasta: (1) zona actual de containers y faenas / vivienda y equipamiento; (2) galpón de acopio / Nueva Vega de Antofagasta; (3) estación de trenes / infraestructura cultural y áreas verdes; (4) zona operación tren / vivienda y equipamiento.

Fuente: Elaboración de los autores.

A modo de síntesis de estas reflexiones, la Figura 9 indica las principales zonas de transformación para avanzar hacia una nueva ciudad puerto de Antofagasta en que además de una apertura hacia la ciudad, el mismo puerto contribuye a resolver problemas urbanos mediante la conexión de nuevos espacios urbanos; tales como vivienda, equipamiento y espacios públicos. Siendo esta una reflexión necesaria, el desarrollo de profundizaciones en el diseño urbano de esta nueva relación puerto-ciudad se puede apoyar tanto de las iniciativas aquí citadas, como de nuevas utopías y exploraciones socio-espaciales.

\section{Conclusiones}

Utopía concreta, democratización y sostenibilidad de la actividad portuaria urbana en la Región de Antofagasta

En este artículo, hemos avanzado hacia elaborar una investigación sobre los posibles futuros del puerto de Antofagasta desde las limitaciones técnicas, políticas y sociales existentes hacia una utopía concreta. En esto, hemos reflexionado sobre cómo incorporar al Puerto de Antofagasta y su paño portuario al tejido urbano del centro histórico de la ciudad, mediante un conjunto de transformaciones institucionales y proyectos urbanos que se configuran como una utopía concreta dado que ensayan un futuro para la ciudad en base a posibilidades técnicas reales pero que necesitan de esfuerzos políticos para su definitiva concreción. En esta última parte, reflexionamos sobre los mecanismos políticos que necesitan ser activados para que la utopía se realice.

Esta utopía concreta necesitaría de transformaciones institucionales importantes, las cuales podrían partir con el empoderamiento municipal en el control sobre el desarrollo y alcances del puerto, conformando una mesa del Consejo de Coordinación de Ciudad Puerto en que la ciudadanía está fuertemente representada a través de la autoridad local y de instancias consultivas vinculantes. Será trabajo de este consejo el llamado a un concurso público para diseñar el espacio urbano del Puerto de Antofagasta, además de emitir la necesidad de trasladar 
las actividades productivas actuales -tanto acopio, trasvasije y almacenamiento de containers- al nuevo puerto de Mejillones, para lo cual será necesaria una acción por parte del Gobierno Regional de Antofagasta. Por su parte, la licitación de diseño comprenderá un llamado a equipos multi-disciplinarios que además de la misma reconversión infraestructural, cuenten con experiencia en la regeneración de centros históricos. Con esto, adecuar el estándar actual del puerto a las exigencias que hiciera la OCDE en el año 2013, como es la comprensión del sistema regional portuario, vial y ferroviario, su diversificación productiva, la apertura del cabotaje, el desarrollo de zonas logísticas, la movilidad y la necesaria mejora de los estándares urbanos (OECD, 2013). Parte de la transformación institucional debe incluir el rol del Estado en el control y planificación de la actividad portuaria.

Cabe señalar que la replicabilidad que surge desde casos nacionales emblemáticos, como Valparaíso en la región central, son adaptables al contexto de la macrozona norte. Esto es posible siguiendo ajustes institucionales, reconocimiento el contexto y el medioambiente, y enfatizando en la comprensión de un sistema regional de puertos estatales donde prime la complementariedad. Será fundamental superar una lógica competitiva por avanzar hacia la colaboración infraestructural y así reducir en parte los impactos generados por los proyectos. A su vez, debe reconocerse el esfuerzo reciente por crear los Consejos Ciudad Puerto, declarados en la Ley 19.542 de 1997, pero que no habían operado desde entonces. Esto es un intento por hacer más representativa la toma de decisiones, pero aun con el desafío de lograr la evolución tecnocrática necesaria, que permita incorporar nuevas variables de diseño y participación.

Siguiendo el ejemplo de la comuna de Recoleta, la municipalidad de Antofagasta deberá ejercer su facultad constitucional para tener y administrar inmuebles. En este caso, sería conveniente que la comuna de Antofagasta construya vivienda de interés social en los paños del puerto y áreas de acopio mientras la propiedad permanezca registrada a nombre del municipio, abriendo opciones para el arriendo a precios relativos al ingreso de los hogares y no adscritos al mercado, contribuyendo así a gestionar el valor de las propiedades con un alto protagonismo público, siguiendo el modelo de Viena. A su vez, la municipalidad debiera gestionar y promover junto al Estado la instalación de comercio y actividades culturales en las nuevas instalaciones que se desarrollarán en los predios que se abran con el traslado del puerto. Si bien, la gestión del área ha de ser municipal, se deberán explorar asociaciones público-privadas para asegurar el éxito de este espacio urbano, que podría tener dificultades para instalarse durante los primeros años de funcionamiento y un subsidio de reemplazo de ganancias podría ayudar. Este tipo de iniciativas ya son parte de la batería de servicios sociales que ofrece la Municipalidad de Antofagasta para microempresarios. Es importante, entonces, considerar que este es un proyecto de largo plazo y para lograr su éxito, el liderazgo, la representatividad y la participación de los habitantes de la comuna es vital. Esto, porque el éxito de esta regeneración no puede recaer en la voluntad política de la autoridad de turno, sino ser un proyecto incrustado entre las prioridades de los vecinos y de la comunidad en general. Es decir, los procesos participativos deberán ser anticipatorios, vinculantes y formativos en relación con lo técnico.

Finalmente, en búsqueda de democratizar la nueva propuesta de la Ciudad Puerto de Antofagasta, más que sugerir un nuevo modelo portuario, parece vital el llamado a un concurso internacional de ideas, procedimiento aplicado este año por el MINVU en el Paseo del Mar Barón, que como procedimiento participativo especializado itere con las mejores ideas, pero cuyo llamado se realice después de un conjunto de diálogos abiertos con y entre las autoridades, entidades privadas, actores relevantes y vecinos que informen a los oferentes cuáles son las prioridades de la ciudad(anía) y las principales preocupaciones sobre qué hacer con este espacio urbano, para lograr su incorporación al tejido socio-espacial de la ciudad. Lo que parece importante es mencionar la importancia de reconsiderar este paño urbano y su entorno inmediato para la construcción de vivienda de interés público, espacios públicos de calidad, áreas de esparcimiento, actividades productivas de menor escala y promover el desarrollo turístico, sostenible y diversificado de la ciudad. Estas son también tareas pendientes que de seguro invitarán al desarrollo de nuevas utopías concretas para Antofagasta [R] 


\section{Referencias}

Aguirre González, M. E. (2004). La arquitectura moderna en Chile: el cambio de la arquitectura en la primera mitad del siglo XX: el rol de la organización gremial de los arquitectos (1907-1942) y el papel de las revistas de arquitectura (1913-1941), Tesis (Doctorado). Universidad Politénica de Madrid, Madrid, España. Recuperado de http://oa.upm.es/478/

Acuto, M., Parnell, S. \& Seto, K. C. (2018). Building a global urban science. Nature Sustainability, 1(1), 2-

\section{4. https://doi.org/10.1038/s41893-017-0013-9}

Al-Farsi, Y. M., Waly, M. I., Al-Sharbati, M. M., AlShafaee, M. A., Al-Farsi, O. A., Al-Khaduri, M. M., ... Deth, R. C. (2013). Levels of heavy metals and essential minerals in hair samples of children with autism in Oman: A case-control study. Biological Trace Element Research, 151(2), 181-186. https://doi.org/10.1007/s12011-012-9553-z

Alarcón, M. (2009). Renovación del frente portuario de Valparaíso. Oportunidad de rearticulación puerto ciudad. Revista Cuaderno Urbano: espacio, cultura y sociedad, 8, 205-225.

Alarcón, M. (2016). Transformación del frente portuario de Talcahuano: Oportunidades para la integración urbana. En Hidalgo, R., Santana, D., Alvarado, V., Arenas, F., Salazar, A., Valdebenito, C. y L. Álvarez (Eds.), Las costas del neoliberalismo. Naturaleza, urbanización y producción inmobiliaria (pp. 144170). Santiago de Chile: Instituto de Geografía, Pontificia Universidad Católica de Chile.

Antofagasta Terminal Internacional SA. (2005). Declaración de Impacto Ambiental "Sistema de Acopio de Concentrados, Puerto Antofagasta." Antofagasta. Recuperado de https://bit.ly/2TeGnUK

Arias, M., Atienza, M. \& Cademartori, J. (2014). Large mining enterprises and regional development in Chile: Between the enclave and cluster. Journal of Economic Geography, 14(1), 73-95. https://doi.org/10.1093/jeg/lbt007

Banco Central. (2018). Cuentas Nacionales. PIB Regional 2017. Recuperado de https://bit.ly/2EOJgYu
Bloch, E. (1988). The utopian function of art and literature: Selected essays. Massachusetts: MIT Press.

Boano, C. \& Vergara-Perucich, J. F. (2017). Neoliberalism and urban development in Latin America: The case of Santiago. London: Routledge.

Bolados, A. (09 de diciembre de 2015). Colegio Médico llama a declarar a Antofagasta como "zona saturada por la contaminación". Diario El Mostrador. https://bit.ly/2CBR8Ls

Borgoño, J.M. y Greiber, R. (1971) Estudio epidemiológico del arsenicismo en la ciudad de Antofagasta. Revista Médica de Chile, 99, 702-707.

Carmona, M. (2014). The Place-shaping Continuum: A Theory of Urban Design Process. Journal of Urban Design, $19 \quad$ (1), 2-36. https://doi.org/10.1080/13574809.2013.854695

Carrillo, I., y Santander, A. (2005). Modernización portuaria en Chile. Síntesis Tecnológica, 2(2), 6369. Recuperado de https://bit.ly/2Vhik9U

CASEN. (2015). Encuesta de caracterización socioeconómica nacional. Ministerio de Desarrollo Social.

Cea, M., Mora, P., Innocenti, D. \& Correa, J. (2017). Mesa de áreas verdes: Resúmen ejecutivo. Centro de Políticas Públicas UC.

Cerda, C. (22 de julio de 2017). Venta y consumo de agua embotellada muestra fuerte alza en Antofagasta y Calama. El Mercurio. Recuperado de https://bit.ly/2AmEluT

Cittá D’Acqua (2000). 10 principios para el desarrollo sostenible de las áreas de "waterfront" urbano. Berlin. Recuperado de https://bit.ly/2Qa9Xci

Cogliano, V. J., Baan, R., Straif, K., Grosse, Y., LaubySecretan, B., El Ghissassi, F., ... \& Galichet, L. (2011). Preventable exposures associated with human cancers. Journal of the National Cancer Institute, 103(24),1827-1839. https://doi.org/10.1093/inci/djr483 
Colegio Médico de Chile (2018). Antofagasta: Colegio Médico llama a descontaminar urgentemente la ciudad. Recuperado de https://bit.ly/2AedVvp

Coleman, N. (2015). Lefebvre for Architects. London: Routledge.

Cuthbert, A. R. (2011). Understanding Cities: Method in Urban Design. London: Routledge.

Daher, A. (2015). Clúster minero sin clúster social: Antofagasta-Chile. Revista de Urbanismo, 7(33), 25-35.https://doi.org/10.5354/0717$\underline{5051.2015 .37964}$

DEIS (2016). Indicadores Básicos de Salud, Chile 2015. Santiago. Recuperado de https://bit.ly/2SnRqv2

De Soto, M. C., \& Hitlan, R. T. (2010). Sorting out the spinning of autism: Heavy metals and the question of incidence. Acta Neurobiologiae Experimentalis, 70(2), 165-176.

Eccles, D., Hamnett, S., Huxley, M., \& McLoughlin, B. (1990). Professionalism and academia: The recognition of town planning courses. Australian Planner, 28(4), 37-43.

Fuentes Hernández, P. (2011). La revista AUCA, 19651986: divulgación de la arquitectura y contribución disciplinar en el epílogo de la modernidad. Arquitetura revista, 7(2), 126-141. https://doi.org/10.4013/arq.2011.72.04

Garcia, P. R. (2008). The role of the port authority and the municipality in port transformation: Barcelona, San Francisco and Lisbon. Planning Perspectives, 23(1), 49-79. https://doi.org/10.1080/02665430701738032

Gaudichaud, F. (2015). Las fisuras del neoliberalismo maduro chileno. Trabajo, "Democracia protegida" y conflictos de clases. Buenos Aires: CLACSO.

Giovinazzi, O., \& Moretti, M. (2010). Port Cities and Urban Waterfront: Transformations and Opportunities. TeMa. Journal of Land Use, Mobility and Environment, 3(SP.09), 57-64. https://doi.org/10.6092/1970-9870/123
Gordon, D. (2001). Waterfront Planning. In International Encyclopedia of the Social \& Behavioral Sciences, 16387-16389.

https://doi.org/http://dx.doi.org/10.1016/B0-08043076-7/04453-3

Harvey, D. (2008). Spaces of Neoliberalization: Towards a Theory of Uneven Geographical Development. Stuttgrat: Franz Steiner Verlag.

Hoyle, B. (2010). Global and Local Change on the PortCity Waterfront. Geographical Review, 90(3), 395417. https://doi.org/10.1111/j.19310846.2000.tb00344.x

Instituto Nacional de Estadísitcas [INE] (2018). Series Estadísticas 2018. Recuperado de http://www.ine.cl/estadisticas/economicas/

Instituto Nacional de Estadísticas [INE). (2018). CENSO 2017.

Ivelic Kusanovic, B., Miranda Zúñiga, A., Pastene Beitya, J., Chávez Gatica, C. y Vásquez Chávez, P. (2017). Relación puerto-ciudad, diseños alternativos al plan maestro de Empresa Portuaria de Valparaíso. Revista de Urbanismo, (36), 97-113. https://doi.org/10.5354/0717-5051.2017.45175

Jamett Sasonov, I. y Paredes Araya, D. (2013). Conmutación de larga distancia en Chile: Estimando el premio por trabajar muy lejos de casa. Estudios de economía, 40(2), 179-209.

Lefebvre, H. (1961). Utopie expérimentale: pour un nouvel urbanisme. Revue française de sociologie, 191-198.

Lefebvre, H. (1969). El derecho a la ciudad. Barcelona: Península.

Lefebvre, H. (1970). La révolution urbaine. Paris: Gallimard.

Lefebvre, H. (1972). La revolución urbana. Madrid: Alianza Editorial.

Lefebvre, H. (1984). Everyday life in the mordern world. Londres: Transaction books. 
Lefebvre, H., Kofman, E., \& Lebas, E. (1996). Writings on cities. Oxford: Blackwell.

Lefebvre, H. (2013). La producción del espacio. Madrid: Capitán Swing.

MINVU (2018). Observatorio Urbano del Ministerio de Vivienda. Recuperado de: http://www.observatoriourbano.cl/

Miraftab, F. (2016). Insurgent Planning: Situating Radical Planning in the Global South. In Readings in Planning Theory: Fourth Edition. https://doi.org/10.1002/9781119084679.ch24

Mondragón, H., y Téllez, A. (2006). Arquitectura y Construcción: Chile, 1945-1950. Una revista de arquitectura moderna.Santiago: Universidad Central de Chile, LOM ediciones.

Monibot, G. (2016). Neoliberalism - the ideology at the root of all our problems. The Guardian, abril, 1-5. Recuperado de https://bit.ly/1SeCVUW

Nawrot, T., Plusquin, M., Hogervorst, J., Roels, H. A., Celis, H., Thijs, L., ... \& Staessen, J. A. (2006). Environmental exposure to cadmium and risk of cancer: a prospective population-based study. The Lancet Oncology, 7(2), 119-126. https://doi.org/10.1016/S1470-2045(06)70545-9

Nuijten, M., Koster, M., \& De Vries, P. (2012). Regimes of spatial ordering in Brazil: Neoliberalism, leftist populism and modernist aesthetics in slum upgrading in Recife. Singapore Journal of Tropical Geography, 33(2), 157-170. https://doi.org/10.1111/j.14679493.2012.00456.x

Organización para la Cooperación y el Desarrollo Económicos [OECD.] (2013). OECD Territorial Reviews: Antofagasta, chile. Paris: OECD. https://doi.org/10.1787/9789264203914-en

Organización para la Cooperación y el Desarrollo Económicos [OECD]. (2018). Vivienda. Recuperado de https://bit.ly/2r80cPq

Observatorio Laboral de Antofagasta [OLAB] (2018). Peso del empleo conmutante sobre el empleo total, 2016. Recuperado de http://olab.mkbm.cl/
Patel, Z., Greyling, S., Parnell, S., \& Pirie, G. (2015). Coproducing urban knowledge: experimenting with alternatives to 'best practice' for Cape Town, South Africa. International Development Planning Review, 37(2), 187-203. https://doi.org/10.3828/idpr.2015.15

Pérez, G. (2014). El Plan Maestro como instrumento de diseño urbano: potencialidades y Antofagasta. AUS (15), 16-21. https://doi.org/10.4206/aus.2014.n15-04

Phelps, N. A., Atienza, M., \& Arias, M. (2015). Encore for the Enclave: The Changing Nature of the Industry Enclave with Illustrations from the Mining Industry in Chile. Economic Geography, 91(2), 119-146. https://doi.org/10.1111/ecge.12086

Pinder, D. (2015). Reconstituting the possible: Lefebvre, utopia and the urban question. International Journal of Urban and Regional Research, 39(1), 2845. https://doi.org/10.1111/1468-2427.12083

Purcell, M. (2013). The Down-Deep Delight of Democracy. Massachusetts - Oxford - West Sussex: John Wiley \& Sons.

Rehner, J., \& Rodríguez, S. (2018). Cities built on copperThe impact of mining exports, wages and financial liquidity on urban economies in Chile. Resources Policy.

(In Press). https://doi.org/10.1016/j.resourpol.2018.05.001

Rodrigo, L. M., y Atienza, M. (2014). Migración y representaciones regionales: discursos sobre la Región de Antofagasta. EURE (Santiago), 40(120), 159-181. https://dx.doi.org/10.4067/S0250$\underline{71612014000200008}$

Riveros, J. (29 de mayo de 2015). Vea si en su comuna la luz es más cara que en otros lugares de Chile. Diario Las Ultimas Noticias, p.22, Santiago de Chile.

Sepúlveda, V., Vega, J. y Delgado, I. (2000). Exposición severa a plomo ambiental en una población infantil de Antofagasta, Chile. Revista Médica de Chile, 128(2), 1-12. https://doi.org/http://dx.doi.org/10.4067/S0034? $\underline{98872000000200014}$ 
SHOA. (2013). Cartas de inundación por Tsunami en Chile. Recuperado de http://www.shoa.cl/php/citsu.php

Sieber, R. T. (1991). Waterfront Revitalization in Postindustrial Port Cities of North America. City \& Society, 5(2), 120-136. https://doi.org/10.1525/city.1991.5.2.120

Sisto, V. (2017). Gobernados por números: El financiamiento como forma de gobierno de la Universidad en Chile. Psicoperspectivas, 16(3), 6475. https://doi.org/10.5027/psicoperspectivasvol16-issue3-fulltext-1086

Smith, A. H., Goycolea, M., Haque, R., \& Biggs, M. Lou. (1998). Marked increase in Bladder and Lung Cancer mortality in a region of northern Chile due to arsenic in drinking water. American Journal of Epidemiology, 147(7), 660-669. https://doi.org/10.1093/oxfordjournals.aje.a0095 $\underline{07}$

Sorkin, M. (2009). The End(s) of Urban Design. En Krieger, A. \& Saunder, W.S (Eds.), Urban Design (pp. 155-182). Minneapolis: University of Minnesota Press.

Stanek, Ł. (2011). Henri Lefebvre on Space, Architecture, Urban Research, and the Production of Theory. Minneapolis: University of Minnesota Press.

Tapia, J., Orrego, R., Valde, J., Tchernitchin, A., Dorador, C., Bolados, A., \& Harrod, C. (2018). Geologic and anthropogenic sources of contamination in settled dust of a historic mining port city in northern Chile: health risk implications. PeerJ, 6 (e4699), 1-30. https://doi.org/10.7717/peerj.4699
TECHO. (2016). Catastro de Campamentos 2016. El número de familias en campamentos no deja de aumentar. Centro de Investigación Social. Santiago. Recuperado de https://bit.ly/2hnXCnK

Texido, A., De La Sotta, P. (2014). Las barreras institucionales que dificultan la inclusión de Valparaíso ciudad puerto. Revista Márgenes, (11)14, 70-74. Recuperado de https://bit.ly/2LDM63X

Ugarte, R. (2010). Teatro del Mar: rehabilitación Paseo del Mar Antofagasta. Disponible en http://repositorio.uchile.cl/handle/2250/100317

Valenzuela, M. (26 de diciembre de 2014). Detectan plomo en la sangre de 107 niños de dos jardines infantiles de Antofagasta. Bio-Bio. Recuperado de https://bit.ly/2VfCDV6

Vergara Perucich, J. F. (2018). Neoliberalandia. Chesterton: Lulu.

Vergara- Perucich, J. F. (2017). The neoliberal urban utopia of Milton Friedman: Santiago de Chile as its realisation. En Boano, C. \& Vergara - Perucich, J.F (Eds.), Neoliberalism and Urban Development in Latin America (pp. 35-52). Londres: Routledge.

Vergara-Perucich, J. F. (2018). Estudio exploratorio sobre asequibilidad económica a la vida cotidiana en principales ciudades de Chile. Serie de Documentos de Trabajo en Economía, 1, Antofagasta.

Zurita, F. (2015). El Sistema Universitario En El Chile Contemporáneo. Educação em Revista, 31(2), 329-343. https://doi.org/10.1590/01024698138059 